\title{
A new modelling approach for unsaturated soils using independent stress variables
}

\author{
Daichao Sheng, Delwyn G. Fredlund, and Antonio Gens
}

\begin{abstract}
Although a number of constitutive models for unsaturated soils exist in the literature, some fundamental questions have not been fully answered. There are questions related to $(i)$ the change of the yield stress with soil suction, (ii) modelling slurry soils, and (iii) the smooth transition between saturated and unsaturated soil states. This paper addresses these questions by proposing an alternative modelling approach. The paper first presents a volumetric model for unsaturated soils. This volumetric model is then used to derive the yield surface in the suction - mean stress space. Hysteresis associated with soil-water characteristic curves is then formulated in the same framework of elastoplasticity. It is shown that volume collapse during wetting and plastic shrinkage during initial drying are both direct results of a suction-dependent hardening law. The proposed model seems to be more flexible in modelling different types of unsaturated soils than most models in the literature. The model can be applied to soils that are dried or loaded from initially slurry conditions, for soils that have low to high air-entry values, and for compacted soils as well.
\end{abstract}

Key words: unsaturated soils, constitutive modelling, elastoplastic, yield stress, hardening law, saturation suction, stress state variables.

Résumé : Quoiqu'un certain nombre de modèles constitutifs pour les sols non saturés existent dans la littérature, des questions fondamentales n'ont pas encore été complètement résolues. Il y a des questions en relation avec $(i)$ le changement de la contrainte limite élastique avec la succion du sol, (ii) la modélisation des boues de sol, et (iii) la transition régulière entre les états de sols saturés et non saturés. Cet article traite de ces questions en proposant une approche alternative de modélisation. Cet article présente d'abord un modèle volumétrique pour les sols non saturés. Ce modèle volumétrique est alors utilité pour dériver la surface de limite élastique dans l'espace succion - contrainte moyenne. L'hystérèse associée avec les courbes caractéristiques sol-eau est alors formulée dans le même cadre d'élastoplasticité. On montre que l'effondrement de volume durant l'humidification et le retrait plastique durant le séchage initial sont tous deux le résultat d'une loi d'écrouissage fonction de la succion. Le modèle proposé semble être plus flexible pour modéliser différents types de sols non saturés que la plupart des modèles dans la littérature. Le modèle peut être appliqué aux sols qui sont secs ou chargés à partir de conditions initiales de boue, aux sols qui ont des valeurs basses à élevées d'entrée d'air et également aux sols compactés.

Mots-clés : sols non saturés, modélisation constitutive, elastoplastique, contrainte limite élastique, loi d'écrouissage, degré de saturation en fonction de la succion, variables d'état de contrainte.

[Traduit par la Rédaction]

\section{Introduction}

Since the pioneering work of Alonso et al. (1990), a number of elastoplastic constitutive models have been developed for modelling the behaviour of unsaturated soils (see, e.g., Gens 1996; Jommi 2000; and Gens et al. 2006 for review). Early models only dealt with the stress-suction-strain relationships of unsaturated soils (e.g., Kohgo et al. 1993; Wheeler and Sivakumar 1995; Bolzon et al. 1996; Cui and Delage 1996; Loret and Khalili 2002). These models are

Received 27 November 2006. Accepted 2 December 2007.

Published on the NRC Research Press Web site at cgj.nrc.ca on 24 April 2008.

D. Sheng. School of Engineering, The University of Newcastle, NSW 2308, Australia.

D.G. Fredlund. ${ }^{1}$ Golder Associates Ltd, Saskatoon,

SK S7N 5A9, Canada.

A. Gens. Department of Geotechnical Engineering \&

Geosciences, Technical University of Catalonia, Barcelona

08034, Spain.

${ }^{1}$ Corresponding author (e-mail: del_fredlund@golder.com). based on the same basic assumptions and largely fall in the same framework as Alonso et al. (1990), although different constitutive equations and different stress variables are used. The model by Alonso et al. (1990), generally referred to as the Barcelona Basic Model (BBM), remains as one of the fundamental models for unsaturated soils. More recent models have incorporated suction-saturation relationships with hysteresis into stress-strain relationships (Wheeler 1996; Dangla et al. 1997; Vaunat et al. 2000; Gallipoli et al. 2003; Wheeler et al. 2003; Sheng et al. 2004; Santagiuliana and Schrefler 2006; Sun et al. 2007a).

Existing elastoplastic models for unsaturated soils usually use a loading-collapse yield surface to define the variation of the apparent preconsolidation stress along the soil suction axis. The apparent preconsolidation stress is usually assumed to increase with increasing suction. Under such a framework, these models are able to reproduce some basic features of unsaturated soil behaviour, for example, the volume change upon wetting (collapse or swelling, depending on the magnitude of applied mean stress) and the increase of shear strength with suction. However, even with these successes, some basic questions have not yet been fully answered. 
One such question is "How does the yield stress change with soil suction?" For a saturated soil, the effective stress principle prevails. Therefore, if a soil is consolidated to a mean stress $p_{\mathrm{y} 0}$ at zero suction (supposing $p_{\mathrm{y} 0}$ is less than the air-entry suction, see Fig. 1), increasing suction to $p_{\mathrm{y} 0}$ at zero mean stress should also lead to plastic yielding. This means that the elastic zone on the plane of mean net stress versus suction should travel along the $45^{\circ}$ line for saturated states. Once the suction is sufficiently high and the soil becomes unsaturated, increasing suction is likely less effective in causing plastic volume change, and the yield surface should therefore drift away from the $45^{\circ}$ line. However, the drift is likely to follow a smooth and continuous curve (shown by the dashed line in Fig. 1). This rationale leads to a somewhat different outcome than the commonly adopted loading-collapse yield surface that assumes the yield stress increases with increasing suction (the dotted line in Fig. 1).

The second question that arises is "Does drying cause plastic volume change of a slurry soil?" Indeed, if the soil is fully saturated, increasing suction has a similar effect on the soil volume as increasing the mean stress. Therefore, drying a slurry soil up to the air-entry suction is similar to consolidating the soil to an equivalent mean stress. This rationale also leads to the conclusion that the initial yield surface of a slurry soil that has never been consolidated must intersect

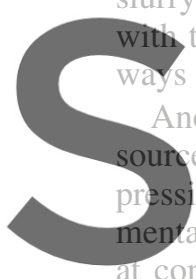

with the suction axis. In other

Ways be at yield during drying.

Another question that needs to

ource and nature of the smooth

al data show that the norm

nstant suctions are usually
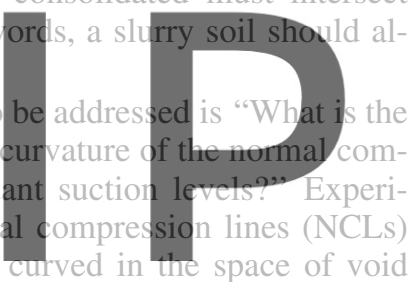

ratio versus logarithmic mean stress when the suction is

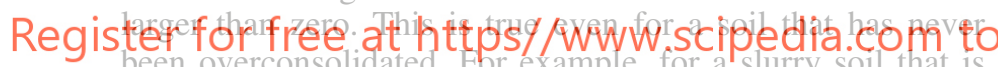

dried to a certain suction and then isotropically compressed at the suction, the isotropic compression line will be curved.

The initial portions of these lines (at relatively low mean net stress) usually become increasingly flatter as suction increases (Jennings and Burland 1962). In the literature, these lines are usually approximated by two asymptotic lines, with one representing the unloading-reloading line (URL) and the other representing the NCL. For the slurry soil mentioned above, the stress and suction applied to the soil has never been reduced. The question is then where does the "unloading-reloading" effect come from. The slope of the NCL is usually considered to be a function of suction, with some data supporting a decreasing slope with increasing suction (Alonso et al. 1990), some supporting an increasing slope (Wheeler and Sivakumar 1995; Matsuoka et al. 2002), and some supporting a more complex function of suction (Josa et al. 1992; Estabragh et al. 2004). More recently, Futai and de Almeida (2005) suggested that the slope of the URLs should also be a function of suction. While these approximations seem to be sufficiently effective, searching for an alternative approach that can lead to a more unified explanation of the slope change of these compression lines is a worthy effort.

The objective of this paper is to address the aforementioned questions by presenting a different approach to model the basic features of unsaturated soil behaviour. The paper first presents a volumetric behaviour model for independent
Fig. 1. Yield surface and elastic zone for saturated soils. $s_{\text {ae }}$, air-entry suction.

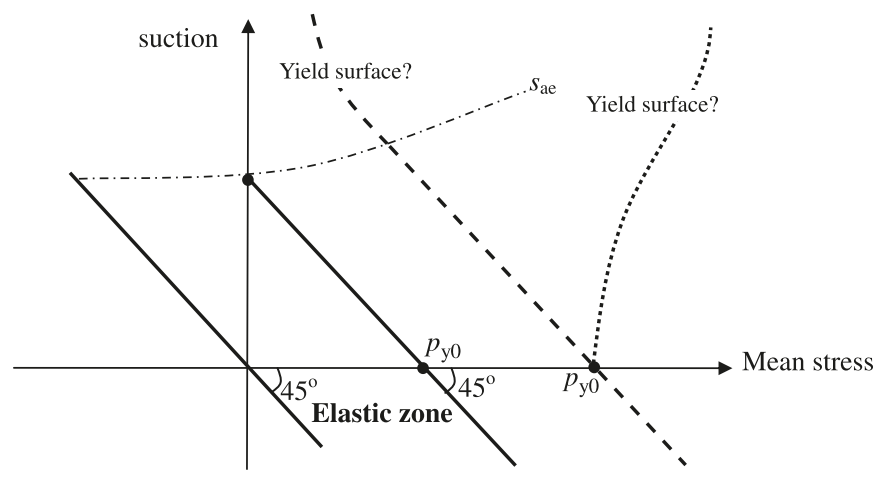

changes of mean net stress and suction. Based on this volumetric relationship, the change of the yield stress with suction and the hardening laws that govern the evolution of the yield surface are derived. Some of the latest developments in combining both stress-strain and suction-saturation relations of unsaturated soils are also incorporated into the proposed model.

\section{Independent stress and strain variables}

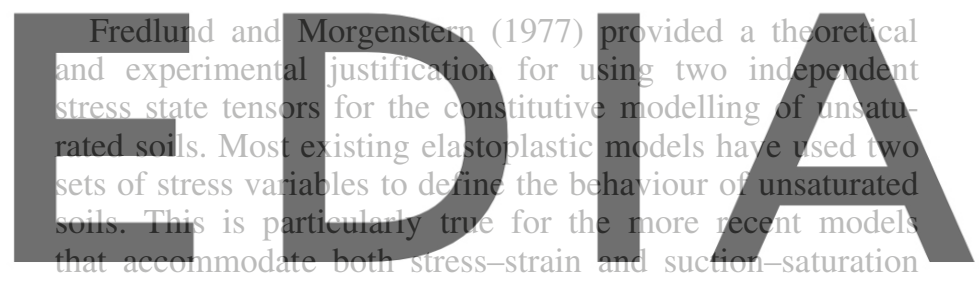

behaviour (Vaunat et al. 2000; Wheeler et al. 2003; Sheng

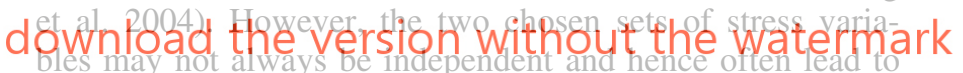

intense debate regarding which approach is better. In this regard, the work by Houlsby (1997) on work-conjugate stressstrain variables has provided some clarification. It was shown that the work-conjugate strain variables to the two sets of independent stress variables (the net stresses and the suction), are the soil skeleton strains and the volumetric water content. Alternatively, the work-conjugate stress variables to the two sets of independent strain variables (the soil skeleton strain and the degree of saturation) are the average stresses and the modified suction ( $n s)$.

In this paper, the constitutive relationships are defined in terms of the two independent stress variables and their work-conjugate strains. The use of the independent stress variables facilitates the study of various stress paths commonly adopted in laboratory testing of unsaturated soils. The two independent stress variables are

$$
\left(\begin{array}{c}
\boldsymbol{\sigma}-\mathbf{m} \mathrm{u}_{\mathrm{a}} \\
\mathrm{u}_{\mathrm{a}}-\mathrm{u}_{\mathrm{w}}
\end{array}\right)=\left(\begin{array}{c}
\overline{\boldsymbol{\sigma}} \\
\mathrm{s}
\end{array}\right)
$$

The work-conjugate strains are

$$
\left(\begin{array}{l}
\boldsymbol{\varepsilon} \\
\theta
\end{array}\right)
$$

In the above equations, $\boldsymbol{\sigma}$ is the total stress vector, $u_{\mathrm{a}}$ is the pore-air pressure, $u_{\mathrm{w}}$ is the pore-water pressure, $\overline{\boldsymbol{\sigma}}$ is the net 
stress vector, $s$ is the soil suction, $\mathbf{m}^{\mathrm{T}}=(1,1,1,0,0,0), \boldsymbol{\varepsilon}$ is the soil skeleton strain vector, and $\theta$ is the volumetric water content.

\section{Constitutive equations}

\section{Volumetric behaviour}

For saturated soils, it is usually assumed that the specific volume, $v$, varies with the mean effective stress, $p^{\prime}=p-u_{\mathrm{w}}$

$$
\text { [1] } \begin{aligned}
\mathrm{d} v & =\mathrm{d}(1+e)=-\lambda_{\mathrm{vp}} \frac{\mathrm{d} p^{\prime}}{p^{\prime}}=-\lambda_{\mathrm{vp}} \frac{\mathrm{d}\left(p-u_{\mathrm{w}}\right)}{\left(p-u_{\mathrm{w}}\right)} \\
& =-\lambda_{\mathrm{vp}} \frac{\mathrm{d} p}{\left(p-u_{\mathrm{w}}\right)}-\lambda_{\mathrm{vp}} \frac{-\mathrm{d} u_{\mathrm{w}}}{\left(p-u_{\mathrm{w}}\right)}
\end{aligned}
$$

where $e$ is the void ratio, $p^{\prime}$ is the mean effective stress, $u_{\mathrm{w}}$ is the pore-water pressure, $\lambda_{\mathrm{vp}}$ is the slope of the NCL for normally consolidated soils, and is replaced by $\kappa_{\mathrm{vp}}$ for the slope of the URL for overconsolidated soils. Equation [1] is integrable in terms of the effective stress, leading to a linear relationship between the specific volume and the logarithmic mean effective stress.

Instead of using eq. [1], it is also common to use a linear relationship between the logarithmic specific volume $\ln v$ and the logarithmic mean effective stress $\ln p^{\prime}$ (e.g., Rouai-

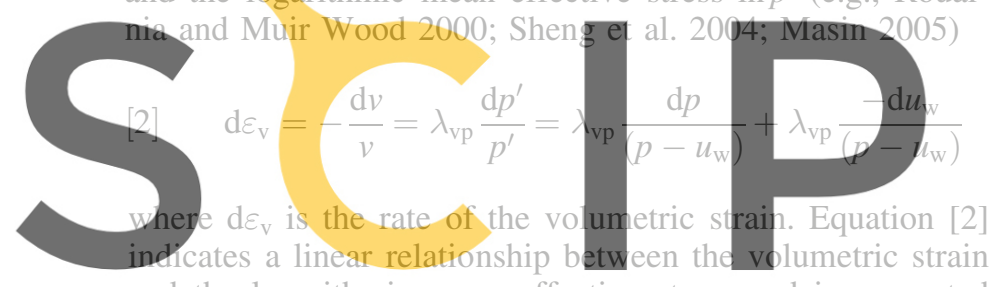
and the logarithmic mean effective stress and is supported

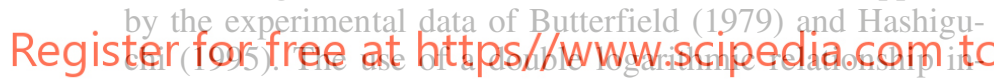
stead of the semilogarithmic relationship is also motivated by the fact that eq. [2] leads to a decoupled model where the instantaneous elastic modulus is independent of the plastic strain (Collins and Kelley 2002). The usual decomposition of the strain vector into elastic and plastic components is only meaningful for decoupled models. Otherwise, eqs. [1] and [2] are similar, and the use of one or the other does not lead to a significant difference, except that some of the later integrations will change.

For unsaturated soils, the volume change due to a suction change may not necessarily be the same as that due to a change in the mean net stress. The equivalent equations then take the form

[3] $\mathrm{d} \varepsilon_{\mathrm{v}}=\lambda_{\mathrm{vp}} \frac{\mathrm{d} \bar{p}}{\bar{p}+s}+\lambda_{\mathrm{vs}} \frac{\mathrm{d} s}{\bar{p}+s}$

where $\bar{p}=p-u_{\mathrm{a}}$ is the mean net stress, $u_{\mathrm{a}}$ is the pore-air pressure, and $s=u_{\mathrm{a}}-u_{\mathrm{w}}$ is the suction. The slope $\lambda_{\mathrm{vs}}$ is identical to the slope $\lambda_{\mathrm{vp}}$ when the soil is fully saturated because decreasing pore-water pressure has a similar effect as increasing the mean stress on a saturated soil. After the soil becomes unsaturated, experimental results show that the slope $\lambda_{\mathrm{vs}}$ gradually decreases to zero at high soil suctions, which is consistent with the common shrinkage test in soil mechanics (i.e., the void ratio changes little for water contents below the shrinkage limit). A schematic view of the relation between the void ratio and the suction is shown in Fig. 2. In the figure, the maximum soil suction that corresponds to full saturation is referred to as the saturation suction. The saturation suction is the same as the air-entry value when the soil is dried from full saturation, but is usually smaller than the air-entry value when the soil is wetted from an unsaturated state.

Experimental evidence for a relationship such as eq. [3]

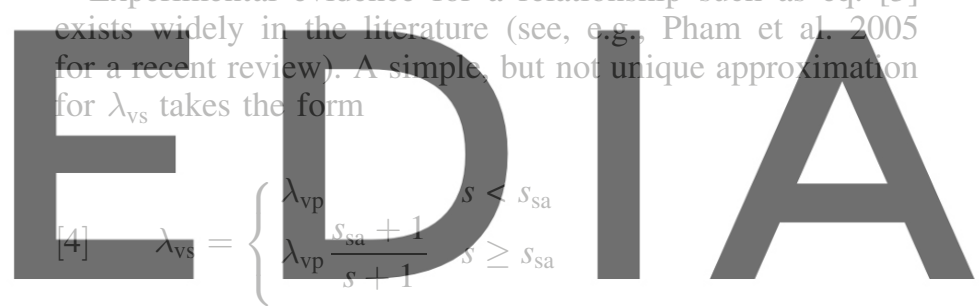

\section{download the wersion suwisthount the 4 wateiemark}

continuous function of suction and will be used in the numerical examples shown later in this paper. Indeed, it would be surprising if such a simplistic function could model all types of unsaturated soils. Therefore, alternative functions with similar features could be used in place of eq. [4]. These functions would not change the patterns of the numerical results and hence not change the main conclusions of the paper, as long as $\lambda_{\mathrm{vs}}$ decreases with increasing suction.

Equation [3] is integrable for suction changes under a constant mean net stress or for stress changes under a constant suction. In such cases, integrating eq. [3] leads to

$$
[5] \quad \ln v=\left\{\begin{aligned}
\ln N-\lambda_{\mathrm{vp}} \ln \left(\frac{\bar{p}+s_{0}}{\bar{p}_{0}+s_{0}}\right) & \mathrm{d} s=0 \\
\ln N-\lambda_{\mathrm{vp}} \ln \left(\frac{\bar{p}_{0}+s}{\bar{p}_{0}+s_{0}}\right) & \mathrm{d} \bar{p}=0 \text { and } s<s_{\mathrm{sa}} \\
\ln N-\lambda_{\mathrm{vp}} \ln \left(\frac{\bar{p}_{0}+s_{\mathrm{sa}}}{\bar{p}_{0}+s_{0}}\right)-\lambda_{\mathrm{vp}} \frac{s_{\mathrm{sa}}+1}{\bar{p}_{0}-1} \ln \left(\frac{s+1}{\bar{p}_{0}+s} \frac{\bar{p}_{0}+s_{\mathrm{sa}}}{s_{\mathrm{sa}}+1}\right) & \mathrm{d} \bar{p}=0, \bar{p}_{0} \neq 1, \text { and } s \geq s_{\mathrm{sa}} \\
\ln N-\lambda_{\mathrm{vp}} \ln \left(\frac{\bar{p}_{0}+s_{\mathrm{sa}}}{\bar{p}_{0}+s_{0}}\right)-\lambda_{\mathrm{vp}}\left(1-\frac{s_{\mathrm{sa}}+1}{s+1}\right) & \mathrm{d} \bar{p}=0, \bar{p}_{0}=1, \text { and } s \geq s_{\mathrm{sa}}
\end{aligned}\right.
$$


Fig. 2. Schematic view of void ratio versus suction under constant net mean stress. (a) Specific volume versus suction under zero stress. (b) Typical shrinkage test result.
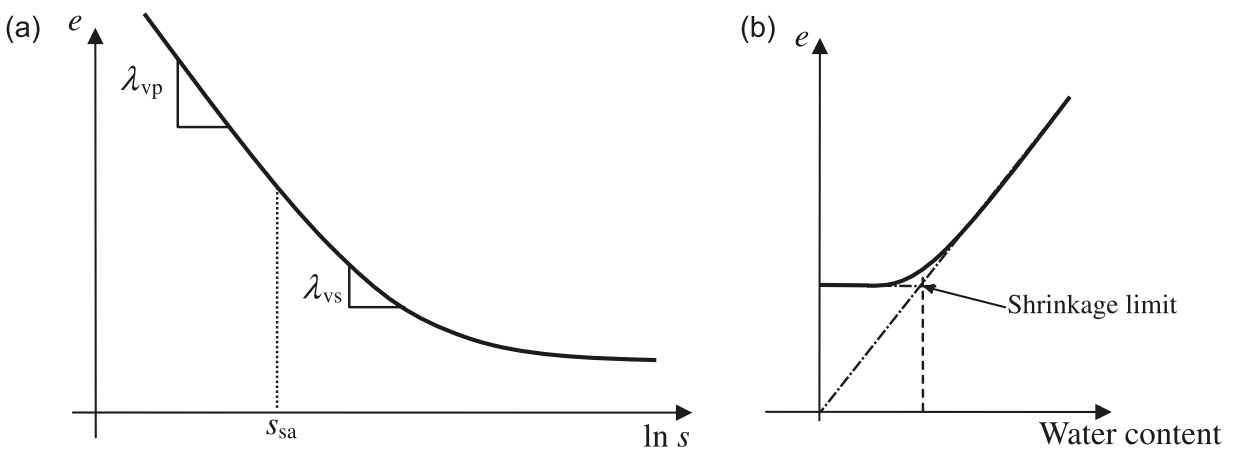

where $N$ is the specific volume at an initial stress state $\left(\bar{p}_{0}, s_{0}\right)$. For nonlinear material behaviour, the stress-strain relations are usually written in incremental form and thus only the rate form (i.e., eq. [3]) is needed. Equations [3] or [5] can be used to generate three-dimensional (3D) plots that show the variation of the specific volume as soil suction and net mean stress change. Such plots are essential for visualization of the yield surface shape and its evolution.

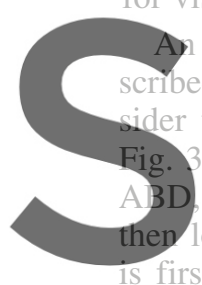
important feature of the by eq. [3] is its stress p wo alternative stress path the slurry soil is first dri oaded to point D. Along loaded to point $\mathrm{C}$ and
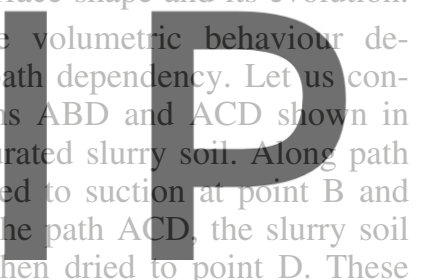

two types of stress paths lead to rather different volumetric

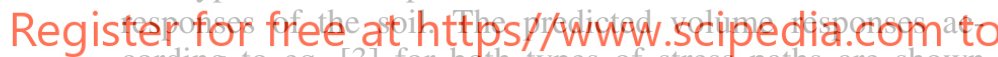
cording to eq. [3] for bdth types of stress paths are shown in Fig. 3. The material parameters used to obtain the results are: $\bar{p}_{0}=1 \mathrm{kPa}, s_{0}=0 \mathrm{kPa}, \lambda_{\mathrm{vp}}=0.1, s_{\mathrm{sa}}=10 \mathrm{kPa}, N=3$.

The $3 \mathrm{D}$ surfaces shown in Fig. 3 are similar to the schematic plots in Fredlund and Morgenstern (1976) and in Fredlund and Rahardjo (1993). The 3D surfaces are also similar to the predictions of the model by Pham et al. (2005), even though the model used in Pham et al. (2005) is quite different from eq. [3]. However, these plots are not state surfaces but are obtained from eq. [5] for specific stress paths and initial conditions.

Figure $3 a$ shows that a soil that is first dried to a high suction becomes almost incompressible. The 3D surface in Fig. $3 a$ is projected onto the $e-\log \bar{p}$ space in Fig. 4 to give a better view of the respective volume changes. Figure 4 shows that when the slurry soil was first dried to a specified suction and then isotropically compressed under a constant suction, the NCLs are no longer straight lines in the $e-\log \bar{p}$ space. Instead, the initial portion of an NCL looks like a URL for an overconsolidated soil, even though the soil has never been unloaded or overconsolidated! It is noteworthy that the URL was not used in obtaining the results. As the suction level increases, the initial portion of the NCL becomes increasingly flatter. If the soil were wetted at point D under a constant mean net stress to full saturation, volume collapse would occur because the void ratio at this point is higher than the void ratio on the NCL for zero suction.
The volumetric behaviour shown in Fig. 4 is well documented for unsaturated clayey soils and is supported by a large amount of experimental data in the literature. For example, the $e-\ln \bar{p}$ curves under constant suctions presented by Matsuoka et al. (2002), Lloret et al. (2003), and Futai and de Almeida (2005) are all similar to those shown in Fig. 4. Figure 5 illustrates that eq. [3] can fit the experimental data of Lloret et al. (2003) on compacted bentonite very well. The

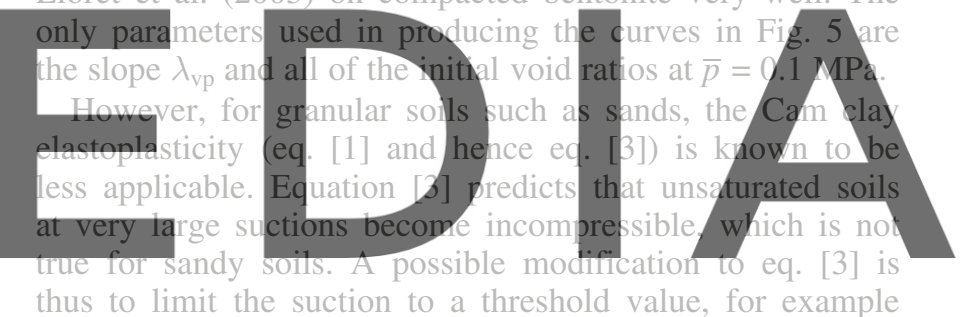

thus to limit the suction to a threshold value, for example

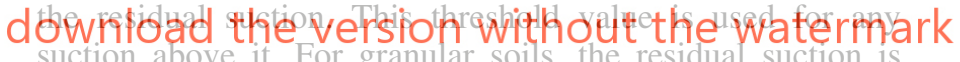
relatively small. Therefore, the compressibility of a granular material is not much affected by the suction.

Such volumetric behaviour is handled quite differently in existing models. For example, it is tackled in the BBM (Alonso et al. 1990) by adopting two asymptotic straight lines, one representing the NCL and the other representing the URL. In such a model, the apparent preconsolidation stress usually has to increase with increasing suction. The slope of the NCL also changes with increasing suction, with some published data supporting a decreasing slope (Alonso et al. 1990) and some supporting an increasing slope (Wheeler and Sivakumar 1995; Matsuoka et al. 2002). The curves in Figs. 4 and 5 were obtained using a constant $\lambda_{\mathrm{vp}}$, and the curvatures change smoothly over a range of suctions.

Figure $3 b$ shows the volume change along stress path ACD where the saturated soil is first compressed to a mean net stress before it is dried. The $2 \mathrm{D}$ projection of Fig. $3 b$ is shown in Fig. 6. The results show that there is little volume change during drying when the soil is first loaded to a high mean net stress (e.g., $1000 \mathrm{kPa}$ ). This is again consistent with similar observations made by numerous researchers (Wheeler and Sivakumar 1995 and Futai and de Almeida 2005). Indeed, the curves in Fig. 6 are of the same pattern as the experimental data of Vicol (1990) cited in Delage and Graham (1996), which is also shown in the figure. 
Fig. 3. Specific volume versus suction and mean net stress (slurry soil, $\bar{p}_{0}=1 \mathrm{kPa}, s_{0}=0 \mathrm{kPa}, N=3, \lambda_{\mathrm{vp}}=0.1, s_{\mathrm{ae}}=10 \mathrm{kPa}$ ). $(a) \mathrm{Stress}$ path ABD. (b) Stress path ACD.

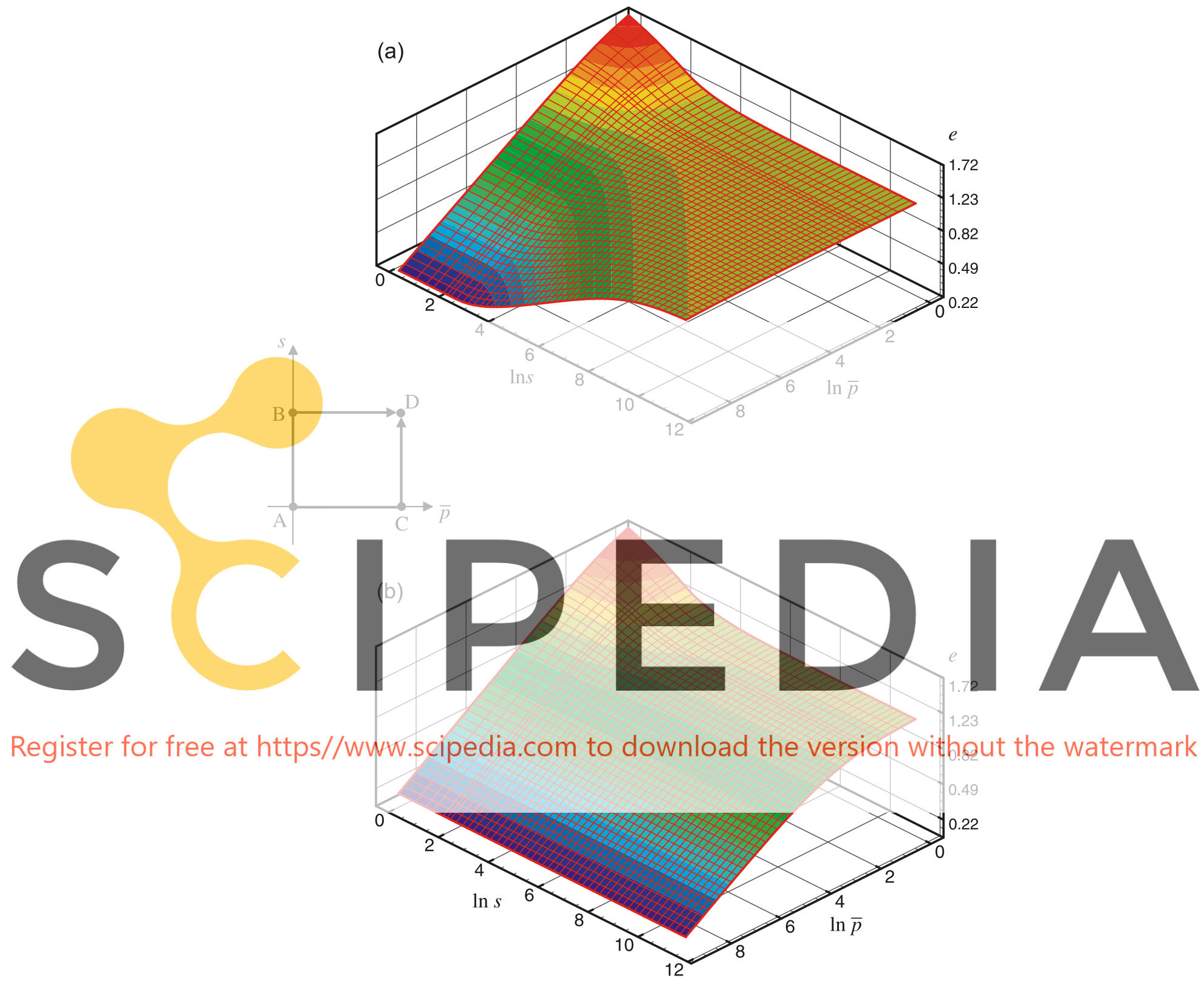

\section{Yield stress and hardening law}

To understand the projection of the yield surface onto the $\bar{p}-\mathrm{s}$ plane for an unsaturated soil, let us start with a yield function for a saturated soil. For simplicity, the Modified Cam Clay (MCC) model (Roscoe and Burland 1968) can be used as a starting point, while the generalization to other single surface models of saturated soils follows in a similar manner. The pore-water pressure can again be separated from the effective stress in the MCC model

[6]

$$
\begin{aligned}
f & =q^{2}-M^{2} p^{\prime}\left(p_{\mathrm{y} 0}-p^{\prime}\right) \\
& =q^{2}-M^{2}\left(p-u_{\mathrm{w}}\right)\left(p_{\mathrm{y} 0}+u_{\mathrm{w}}-p\right) \equiv 0
\end{aligned}
$$

where $f$ is the yield function, $q$ is the deviator stress, $M$ is the slope of the critical state line, $p^{\prime}$ is the effective mean stress, and $p_{\mathrm{y} 0}$ is the preconsolidation stress or the yielding mean stress at zero pore-water pressure. If the yield surface is projected onto the $p-u_{\mathrm{w}}$ plane, the elastic zone is bounded by the two $45^{\circ}$ lines, as shown in Fig. 7. Equation [6] can be rewritten as

[7] $f=q^{2}-M^{2}\left(p-p_{0}\right)\left(p_{\mathrm{y}}-p\right) \equiv 0$

where $p_{\mathrm{y}}=p_{\mathrm{y} 0}+u_{\mathrm{w}}$ is the yielding mean stress, and $p_{0}=u_{\mathrm{w}}$ is the $45^{\circ}$ line that goes through zero (see Fig. 7).

Once the soil suction is above the saturation suction, increasing suction is likely to be less effective as increasing stress in causing plastic volume change. Therefore, the bounding lines are expected to drift away from the $45^{\circ}$ lines. The equivalent MCC yield function for unsaturated soils then takes the form

[8] $\quad f=q^{2}-M^{2}\left[\bar{p}-\bar{p}_{0}(s)\right]\left[\bar{p}_{\mathrm{y}}(s)-\bar{p}\right] \equiv 0$

where both $\bar{p}_{\mathrm{y}}$ and $\bar{p}_{0}$ are expected to be functions of the 
Fig. 4. Normal compression lines at different suctions (slurry soil, $N=3, \lambda_{\mathrm{vp}}=0.1, s_{\mathrm{ae}}=10 \mathrm{kPa}$ ).

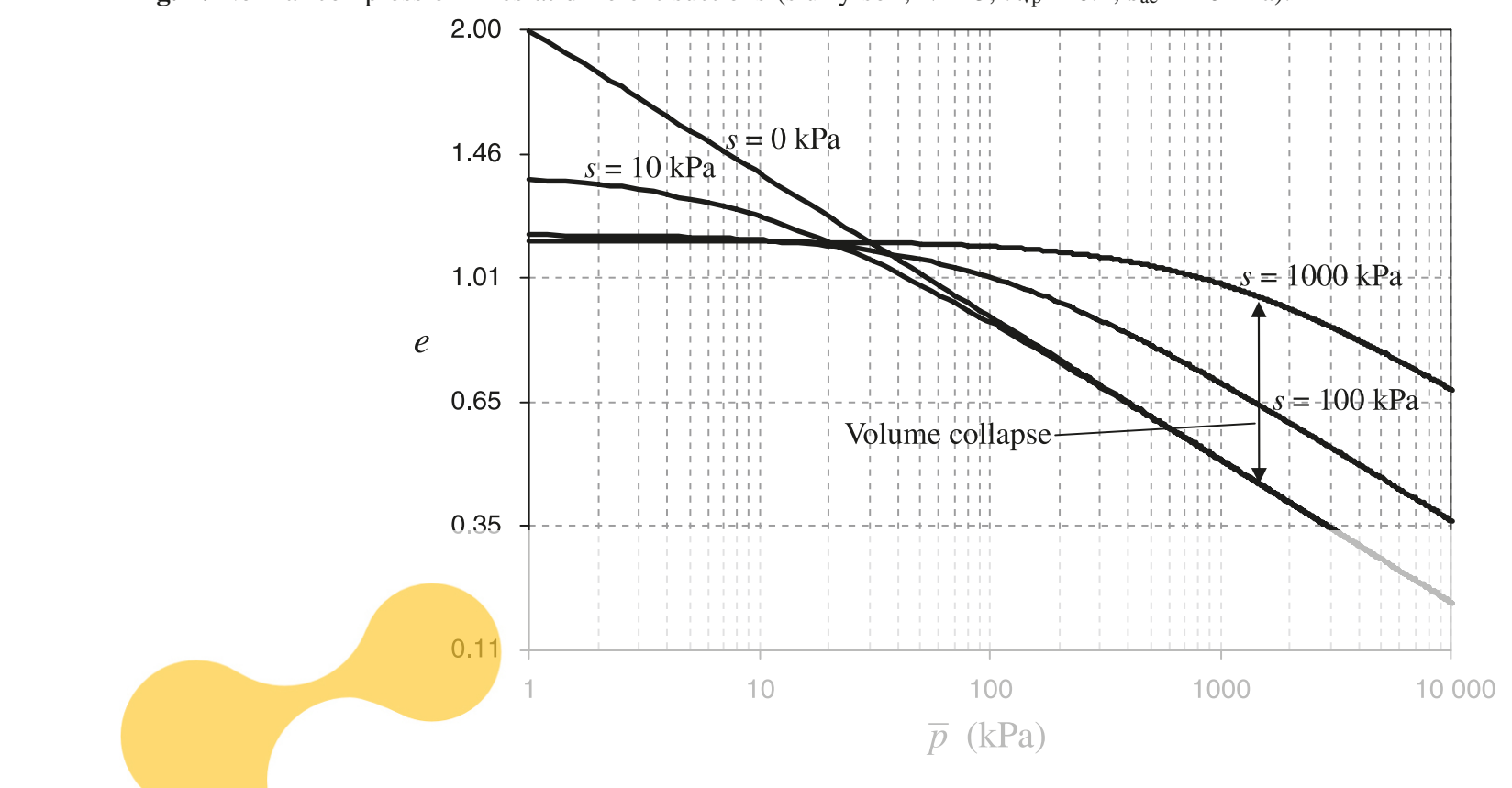

Fig. 5. Comparison of eq. [3] with the experimental data of Lloret et al. (2003). The curve of $s=0.7 \mathrm{MPa}$ corresponds to the data of $s=$
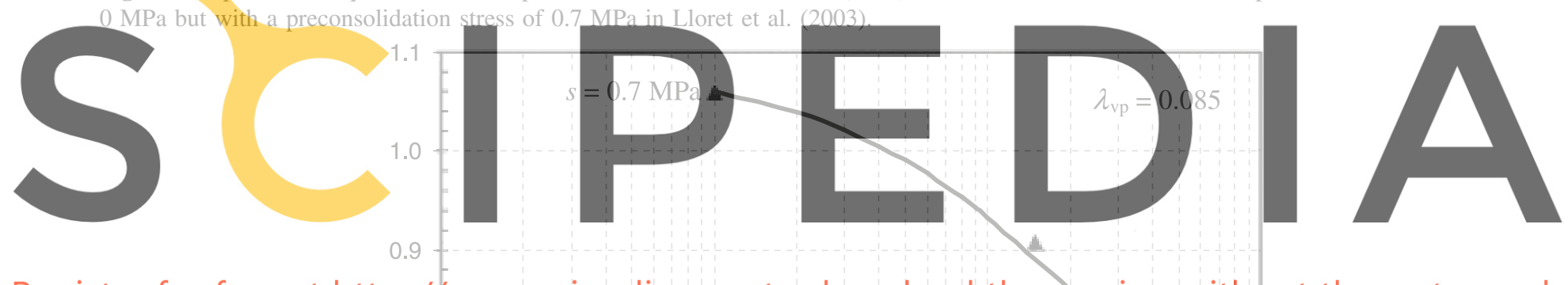

Register for free at https//www.scipedia

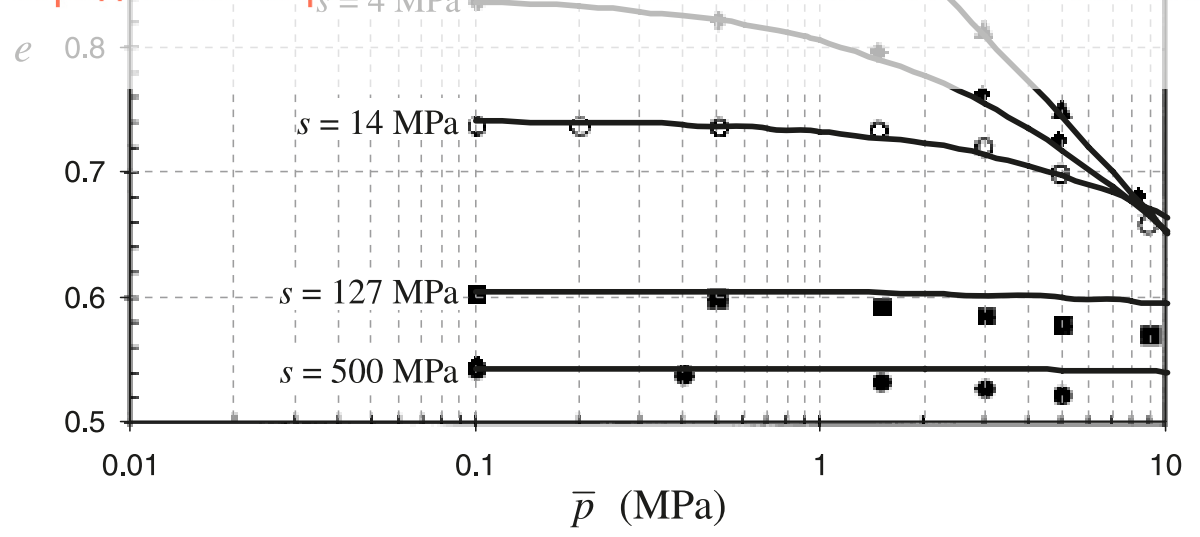

suction. The shear strength parameter $M$ can also be a function of the suction, if necessary.

To understand the evolution of the yield surface for suctions above the saturation suction, we replotted the 3D surfaces in Fig. 3 in arithmetic scales of soil suction and mean net stress in Fig. 8. The saturation suction is also changed to $100 \mathrm{kPa}$, to make it more visible on the arithmetic plots. The contours of the void ratio can be seen to follow the $45^{\circ}$ line for suctions below the saturation suction, but then drift away differently depending on the stress path. For stress path $\mathrm{ABD}$, the void ratio at point $\mathrm{D}$ can be higher or lower than the void ratio at point $\mathrm{C}$, depending on the suction level at point $\mathrm{D}$. For stress path $\mathrm{ACD}$, the void ratio at point $\mathrm{D}$ is always lower than that at point $\mathrm{C}$.

The contours of the void ratio are not exactly representative of the yield surfaces. Rather, the yield surfaces are represented by the contours of the plastic volumetric strain for isotropically hardening materials. Therefore, the elastic volume change has to be considered. Following the framework of critical state soil mechanics and prior discussions, we adopt the following relationship for elastic (recoverable) volume change caused by stress and suction changes: 
Fig. 6. Void ratio versus suction along stress path ACD (in the upper right corner, experimental data by Vicol 1990 are shown for comparison). NC, normally consolidated; OC, overconsolidated.
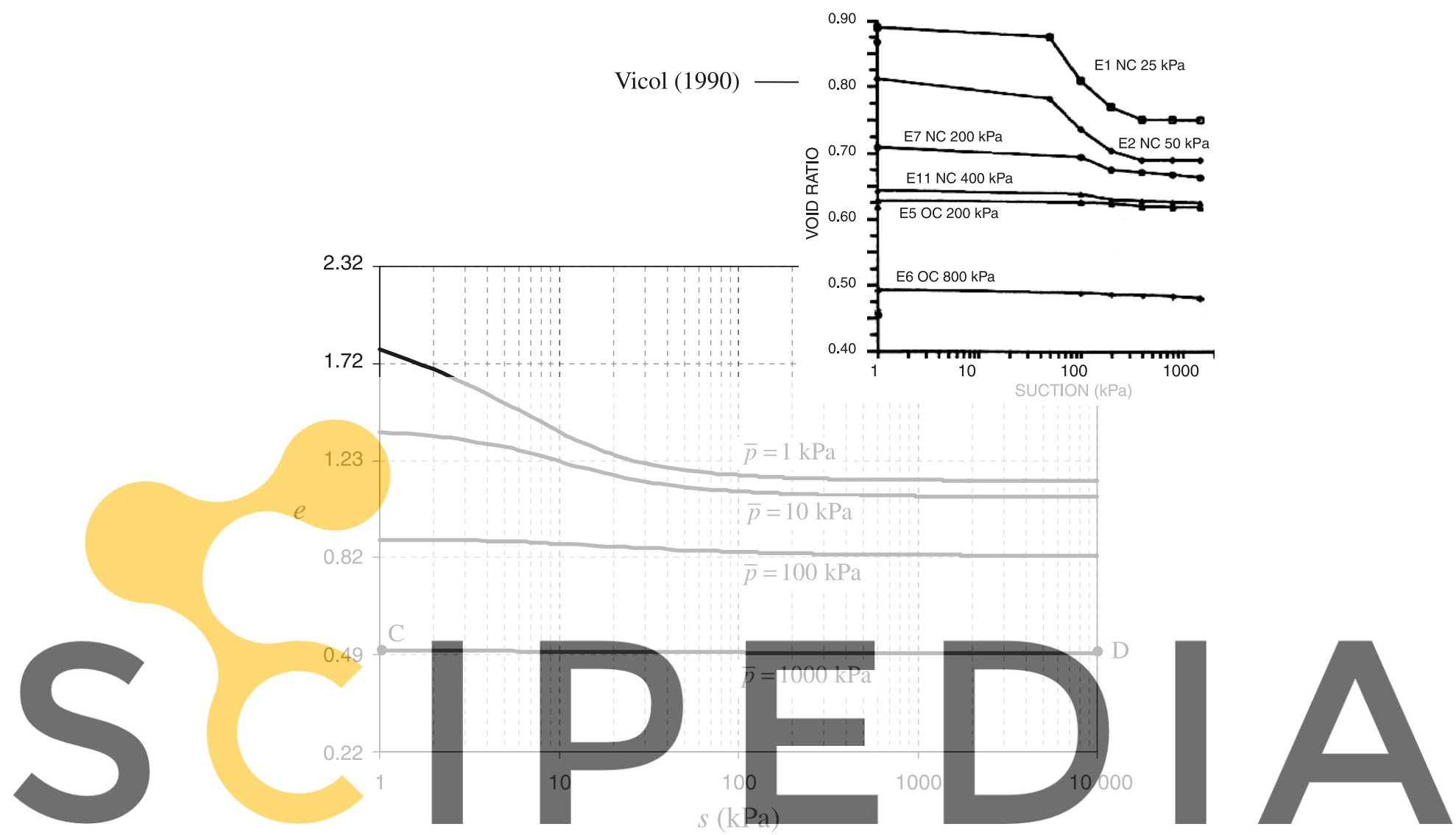

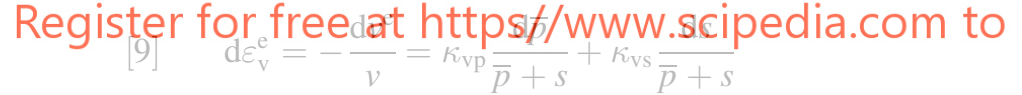

where the siope $\kappa_{\mathrm{vs}}$ is again identical to the siope $\kappa_{\mathrm{vp}}$ when the suction is less than the saturation suction and then gradually decreases to zero as the suction increases above the saturation suction. A simple, but not unique, approximation would be of the following form:

$[10] \quad \kappa_{\mathrm{vs}}= \begin{cases}\kappa_{\mathrm{vp}} & s<s_{\mathrm{sa}} \\ \kappa_{\mathrm{vp}} \frac{s_{\mathrm{sa}}+1}{s+1} & s \geq s_{\mathrm{sa}}\end{cases}$

With eqs. [3] and [9], it is now possible to derive the projection of the yield surface onto the $\bar{p}-s$ plane and the hardening laws that govern the evolution of the yield surface. Let us commence with a soil that has been consolidated to $\bar{p}_{\mathrm{y} 0}$ under zero suction and study how the yield stress changes as the suction increases. The plastic volumetric strain should be zero along the initial yield surface, giving rise to the following equation:

$$
\begin{aligned}
\left(\lambda_{\mathrm{vp}}-\kappa_{\mathrm{vp}}\right) \frac{\mathrm{d} \bar{p}_{\mathrm{y}}}{\bar{p}_{\mathrm{y}}+s}+\left(\lambda_{\mathrm{vs}}-\kappa_{\mathrm{vs}}\right) \frac{\mathrm{d} s}{\bar{p}_{\mathrm{y}}+s} & =0 \\
\Rightarrow \frac{\mathrm{d} \bar{p}_{\mathrm{y}}}{\mathrm{d} s} & =-\frac{\lambda_{\mathrm{vs}}-\kappa_{\mathrm{vs}}}{\lambda_{\mathrm{vp}}-\kappa_{\mathrm{vp}}}
\end{aligned}
$$

ownlaad thempersilonifwitheut: the watermark tial yield stress $\bar{p}_{\mathrm{y}}$ at an arbitrary suction $s$ for this soil. This equation can be integrated along the yield surface from $\left(\bar{p}_{\mathrm{y} 0}, 0\right)$ to $\left(\bar{p}_{\mathrm{y}}, s\right)$ on the $\bar{p}-s$ plane, leading to

$$
\bar{p}_{\mathrm{y}}= \begin{cases}\bar{p}_{\mathrm{y} 0}-s & s<s_{\mathrm{sa}} \\ \bar{p}_{\mathrm{y} 0}-s_{\mathrm{sa}}-\left(s_{\mathrm{sa}}+1\right) \ln \frac{s+1}{s_{\mathrm{sa}}+1} & s \geq s_{\mathrm{sa}}\end{cases}
$$

Similarly, eq. [11] can also be integrated from $(0,0)$ to $\left(\bar{p}_{0}\right.$, $s)$ to give $\bar{p}_{0}$

$$
\bar{p}_{0}= \begin{cases}-s & s<s_{\mathrm{sa}} \\ -s_{\mathrm{sa}}-\left(s_{\mathrm{sa}}+1\right) \ln \frac{s+1}{s_{\mathrm{sa}}+1} & s \geq s_{\mathrm{sa}}\end{cases}
$$

The yield functions so found define the initial elastic zone for a soil that was consolidated at zero suction. Figure 9 illustrates how the initial elastic zone moves with soil suction. In the figure, the soil has a saturation suction of $100 \mathrm{kPa}$ and was consolidated to $300 \mathrm{kPa}$ at zero suction. If such a soil is dried at zero net mean stress, plastic volume change will not occur until the soil suction reaches $730 \mathrm{kPa}$.

The yield surface $\bar{p}_{\mathrm{y}}$ shown in Fig. 9 is only valid for a soil that was initially consolidated to $300 \mathrm{kPa}$ at zero suction. A slurry soil that has never been consolidated has an 
Fig. 7. Yield surface for saturated soils (MCC model).
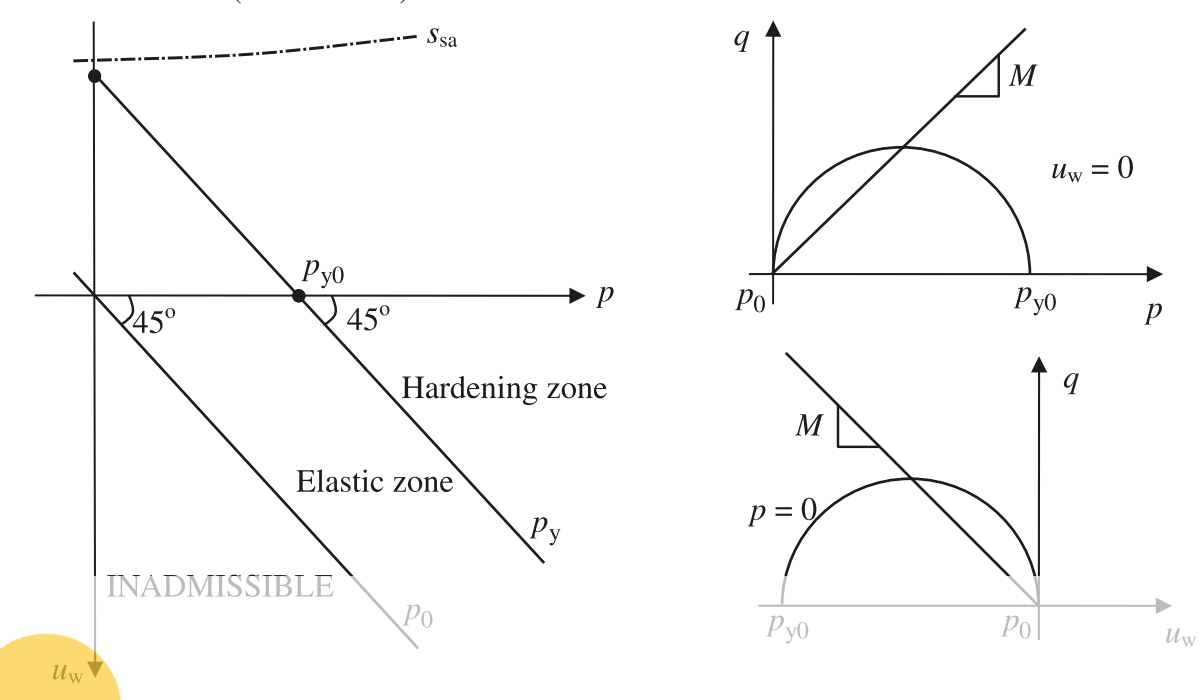

Fig. 8. Contours of void ratio on the $\bar{p}-s$ plane (slurry soil, $N=3, \lambda_{\mathrm{vp}}=0.1, s_{\mathrm{ae}}=100 \mathrm{kPa}$ ). (a) Following stress path ABD - slurry soil dried to different suctions and then isotropically compressed. (b) Following stress path ACD - slurry isotropically compressed to different mean stresses and then dried.
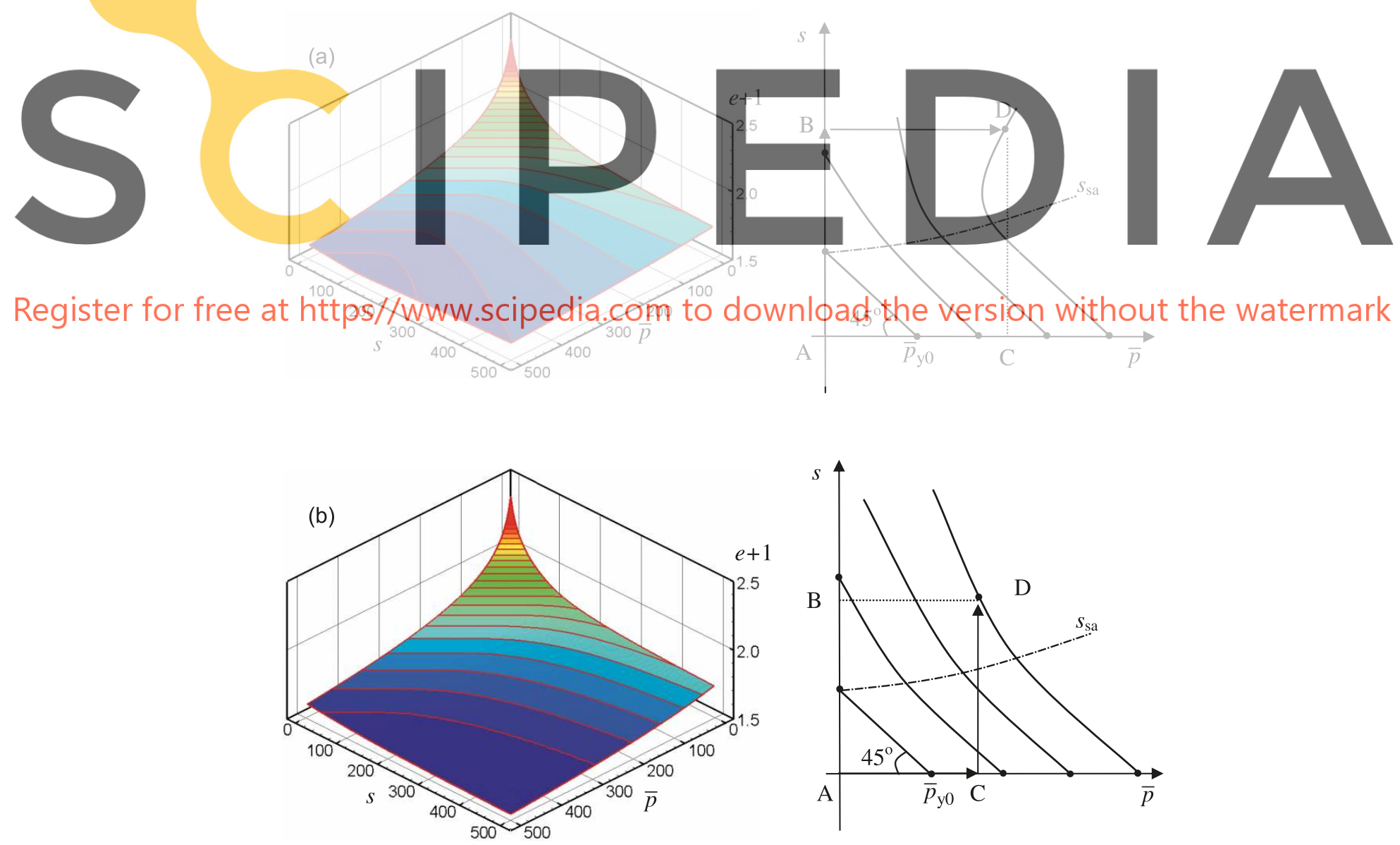

initial yield surface that is a single point at the origin. Drying of such a slurry soil under a constant mean net stress leads to a slightly different yield surface (as will be demonstrated later). If a soil is loaded to plastic yielding at soil suctions higher than the saturation suction (e.g., a com- pacted soil), the yield surface will evolve to a quite different shape; this too will be shown later. The evolution of the yield surface is governed by a hardening law.

The equation for $\bar{p}_{0}$ (i.e., eq. [13]) also defines the socalled apparent cohesion 
$[14]$

$$
\begin{aligned}
c & =-\bar{p}_{0} \tan \phi \\
& = \begin{cases}s \tan \phi & s<s_{\mathrm{sa}} \\
\tan \phi\left[s_{\mathrm{sa}}+\left(s_{\mathrm{sa}}+1\right) \ln \frac{s+1}{s_{\mathrm{sa}}+1}\right] & s \geq s_{\mathrm{sa}}\end{cases}
\end{aligned}
$$

where $\phi$ is the friction angle of the soil due to stress. It should be noted that the function for $\bar{p}_{0}$ never changes in the stress-suction space. There is no hardening or softening associated with this yield stress.

For isotropically hardening material, $\bar{p}_{\mathrm{y}}$ changes according to the plastic volumetric strain. From eqs. [3] and [9], we have

$$
\mathrm{d} \varepsilon_{\mathrm{v}}^{\mathrm{p}}=\frac{\lambda_{\mathrm{vp}}-\kappa_{\mathrm{vp}}}{\bar{p}+s} \mathrm{~d} \bar{p}+\frac{\lambda_{\mathrm{vs}}-\kappa_{\mathrm{vs}}}{\bar{p}+s} \mathrm{~d} s
$$

Equation [15] is the hardening law that governs the evolution of the yield surface. Therefore, the evolution of $\bar{p}_{\mathrm{y}}$ under a constant suction $s$ is governed by the following equation:

$$
\mathrm{d} \varepsilon_{\mathrm{v}}^{\mathrm{p}}=\frac{\lambda_{\mathrm{vp}}-\kappa_{\mathrm{vp}}}{\left(\bar{p}_{\mathrm{y}}+s\right)} \mathrm{d} \bar{p}_{\mathrm{y}}
$$

Equation [16] shows that the evolution of $\bar{p}_{\mathrm{y}}$ depends on the suction level. If the soil in Fig. 9 is isotropically loaded to plastic yielding at different suction levels, a new yield surface then represents a contour of the total plastic volumetric strain. This means that the total plastic volumetric strain will be the same when every point on the current yield surface $\bar{p}_{\mathrm{y}}$ is loaded to a new yield surface $\bar{p}_{\mathrm{yn}}$ under a constant suction. Therefore, we have

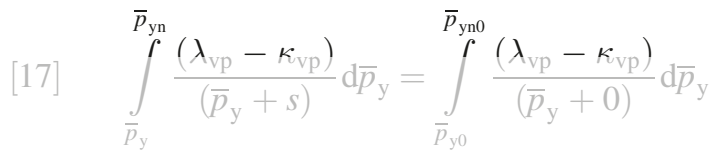

The above equation can be integrated, leading to

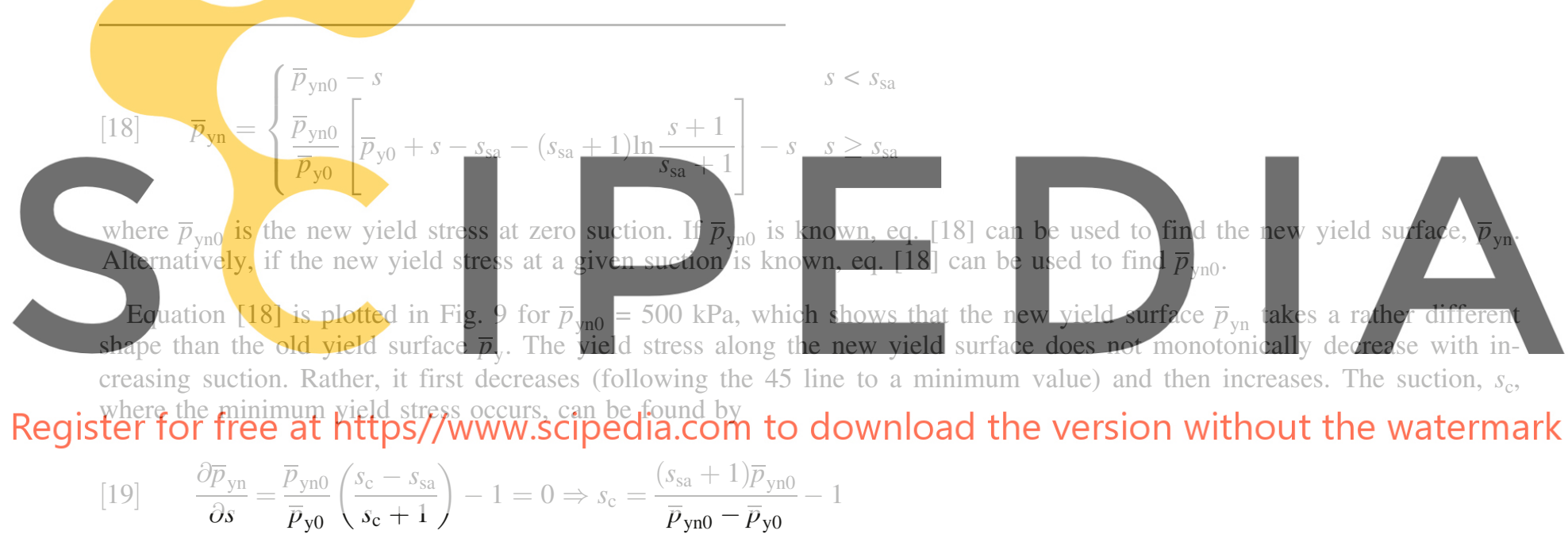

It then becomes clear that, only if the soil is wetted from suctions higher than $s_{\mathrm{c}}$, collapse will occur. Therefore, $s_{\mathrm{c}}$ represents the minimum collapsible suction. The new yield surface shown in Fig. 9 confirms the void ratio contours shown in Fig. $8 a$. Note that the soil in Fig. $8 a$ is a slurry soil that was never consolidated.

Alternatively, drying from the current yield surface under a constant mean net stress will invoke the hardening law

$$
\mathrm{d} \varepsilon_{\mathrm{v}}^{p}=\frac{\lambda_{\mathrm{vs}}-\kappa_{\mathrm{vs}}}{\left(\bar{p}+s_{\mathrm{y}}\right)} \mathrm{d} s_{\mathrm{y}}
$$

where $s_{\mathrm{y}}$ is the suction value along the yield surface $\bar{p}_{\mathrm{y}}$. Equation [12] can be rewritten in terms of $s_{\mathrm{y}}$

$$
s_{\mathrm{y}}= \begin{cases}\bar{p}_{\mathrm{y} 0}-\bar{p} & \bar{p}>\bar{p}_{\mathrm{y} 0}-s_{\mathrm{sa}} \\ \left(s_{\mathrm{sa}}+1\right) \exp \left(\frac{\bar{p}_{\mathrm{y} 0}-s_{\mathrm{sa}}-\bar{p}}{s_{\mathrm{sa}}+1}\right)-1 & \bar{p} \leq \bar{p}_{\mathrm{y} 0}-s_{\mathrm{sa}}\end{cases}
$$

Similarly, the total plastic volumetric strain will be the same if every point on the current yield surface $s_{\mathrm{y}}$ is dried to a new yield surface $s_{\mathrm{yn}}$ under a constant mean net stress

$$
\int_{s_{\mathrm{y}}}^{s_{\mathrm{yn}}} \frac{\left(\lambda_{\mathrm{vs}}-\kappa_{\mathrm{vs}}\right)}{\left(\bar{p}+s_{\mathrm{y}}\right)} \mathrm{d} s_{\mathrm{y}}=\int_{\bar{p}_{\mathrm{y} 0}-\bar{p}_{\mathrm{yn} 0}}^{0} \frac{\left(\lambda_{\mathrm{vp}}-\kappa_{\mathrm{vp}}\right)}{\left(\bar{p}_{\mathrm{yn} 0}+s_{\mathrm{y}}\right)} \mathrm{d} s_{\mathrm{y}}
$$


The integration becomes more complex because $\left(\lambda_{\mathrm{vs}}-\kappa_{\mathrm{vs}}\right)$ depends on the suction. The final solution is given by

$$
s_{\mathrm{yn}}= \begin{cases}\frac{A \bar{p}-1}{1-A} & \bar{p} \leq \bar{p}_{\mathrm{y} 0}-s_{\mathrm{sa}} \\ \frac{B \bar{p}-1}{1-B} & \bar{p}_{\mathrm{yn} 0}-s_{\mathrm{sa}} \geq \bar{p}>\bar{p}_{\mathrm{y} 0}-s_{\mathrm{sa}} \\ \bar{p}_{\mathrm{yn} 0}-\bar{p} & \bar{p}>\bar{p}_{\mathrm{yn} 0}-s_{\mathrm{sa}}\end{cases}
$$

where

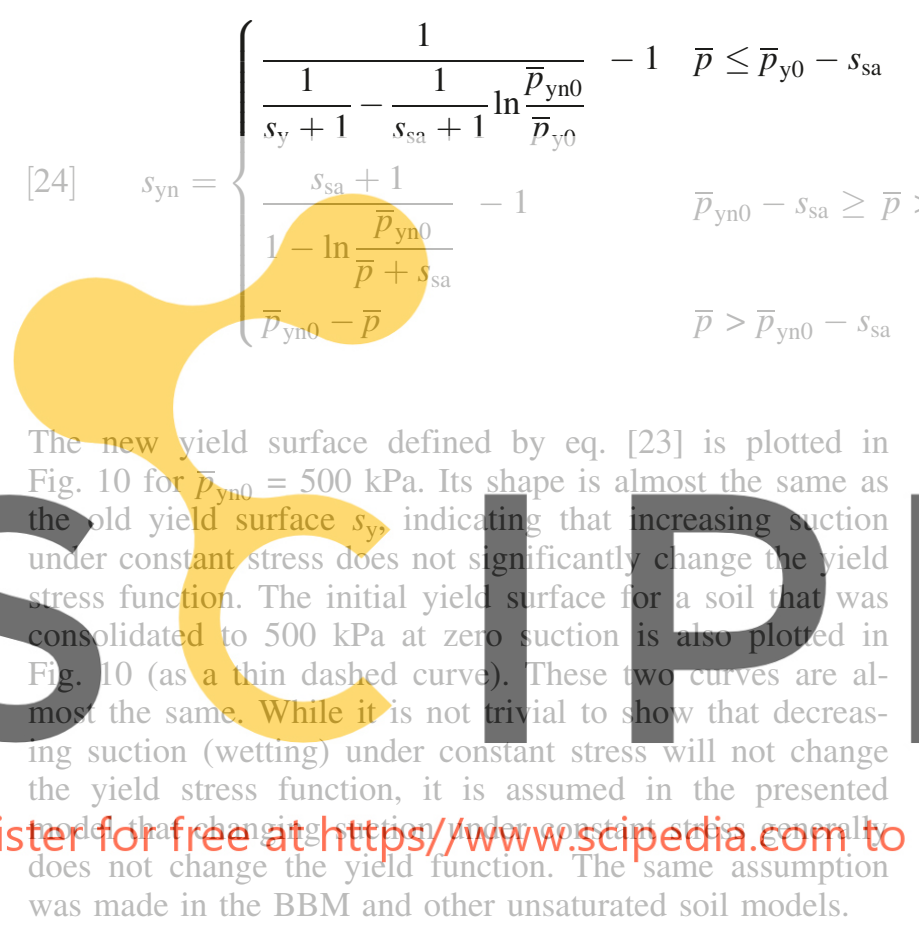

Note that eqs. [23] or [24] may become undefined for small mean net stresses as the yield surface approaches a vertical line. The shape of the curve in Fig. 10 confirms the void ratio contour shown in Fig. $8 b$. It becomes clear that no collapse would occur in this case if the soil is wetted under a constant mean net stress.

It is noted that the approach used in this section for deriving the yield surface and hardening laws can also be applied to other existing models. Appendix A illustrates an application to the BBM (Alonso et al. 1990).

\section{Volume collapse during wetting}

As previously mentioned, it is difficult to prove that decreasing suction (wetting) under constant stress will not change the yield stress function. However, as in other existing models, it is assumed that changing suction under constant stress generally does not change the yield function. With such an assumption, the volume change during wetting under constant mean stresses will occur under two conditions: $(i)$ the yield stress increases with increasing suction (which ensures the wetting path is elastoplastic), and (ii) the NCL for an unsaturated state is above the normal compression for the saturated state. These conditions apply to all models including BBM and the presented model. If these

$$
\begin{aligned}
& \mathrm{A}=\left(\frac{\overline{\mathrm{p}}_{\mathrm{yn} 0}}{\overline{\mathrm{p}}_{\mathrm{y} 0}}\right)^{\frac{\overline{\mathrm{p}}-1}{\mathrm{sa}_{\mathrm{s}}+1}} \frac{\mathrm{s}_{\mathrm{y}}+1}{\mathrm{~s}_{\mathrm{y}}+\overline{\mathrm{p}}} \\
& \mathrm{B}=\left(\frac{\overline{\mathrm{p}}_{\mathrm{yn} 0}}{\overline{\mathrm{p}}+\mathrm{s}_{\mathrm{sa}}}\right)^{\frac{\overline{\mathrm{p}}-1}{\mathrm{~s}_{\mathrm{s}}+1}} \frac{\mathrm{s}_{\mathrm{sa}}+1}{\mathrm{~s}_{\mathrm{sa}}+\overline{\mathrm{p}}}
\end{aligned}
$$

Note that eq. [23] is not defined when $\bar{p}=1$. The following function can then be used:

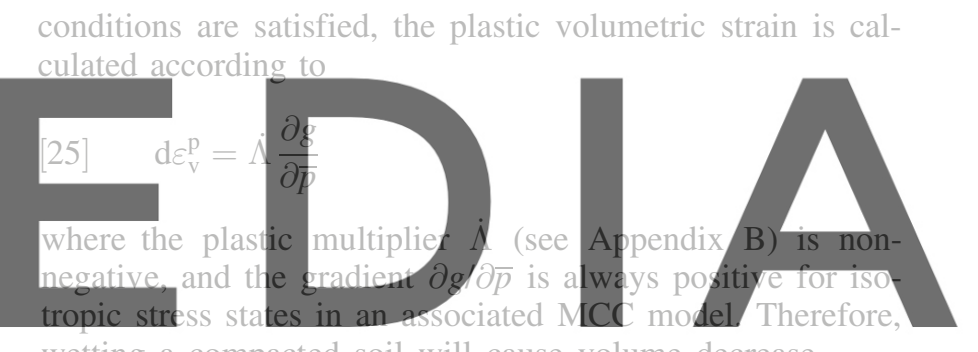

wetting a compacted soil will cause volume decrease.

\section{downteas of that-versionamithout the watermark}

So far the relationships between the soil skeleton strain and the stress state variables have been established. One missing part of the model is the relationship between the volumetric water content and the stress state variables. Extensive research has been done on the soil-water characteristics of a soil, first in the field of soil physics and later within geotechnical engineering (see, e.g., Hillel 1971; Fredlund and Rahardjo 1993). The soil suction versus water content relationship is affected by the mean net stress primarily through its influence on the saturation suction and the rate of desaturation (see, e.g., Vanapalli et al. 1996; $\mathrm{Ng}$ and Pang 2000). As a first approximation, let us assume a piecewise linear relationship between the degree of saturation $S_{\mathrm{r}}$ and the logarithmic soil suction

[26] $\mathrm{d} S_{\mathrm{r}}=-\lambda_{\mathrm{ws}} \frac{\mathrm{d} s}{s}$

where the slope $\lambda_{\mathrm{ws}}$ may change with suction. For soil suctions below the saturation suction, the soil is saturated and the degree of saturation remains essentially constant. For soil suctions larger than the residual suction, the water content gradually decreases to zero at a suction of $10^{6} \mathrm{kPa}$ (Fredlund and Rahardjo 1993). The slope $\lambda_{\mathrm{ws}}$ is assumed to be constant between the air-entry value and the residual suction for a drying soil (Wheeler et al. 2003). Therefore, we have, as shown in Fig. 11 
Fig. 9. Initial yield surface for a soil that was consolidated to $300 \mathrm{kPa}$ at zero suction and its evolution when the soil is then loaded at different suction levels $\left(s_{\mathrm{ae}}=100 \mathrm{kPa}\right)$.

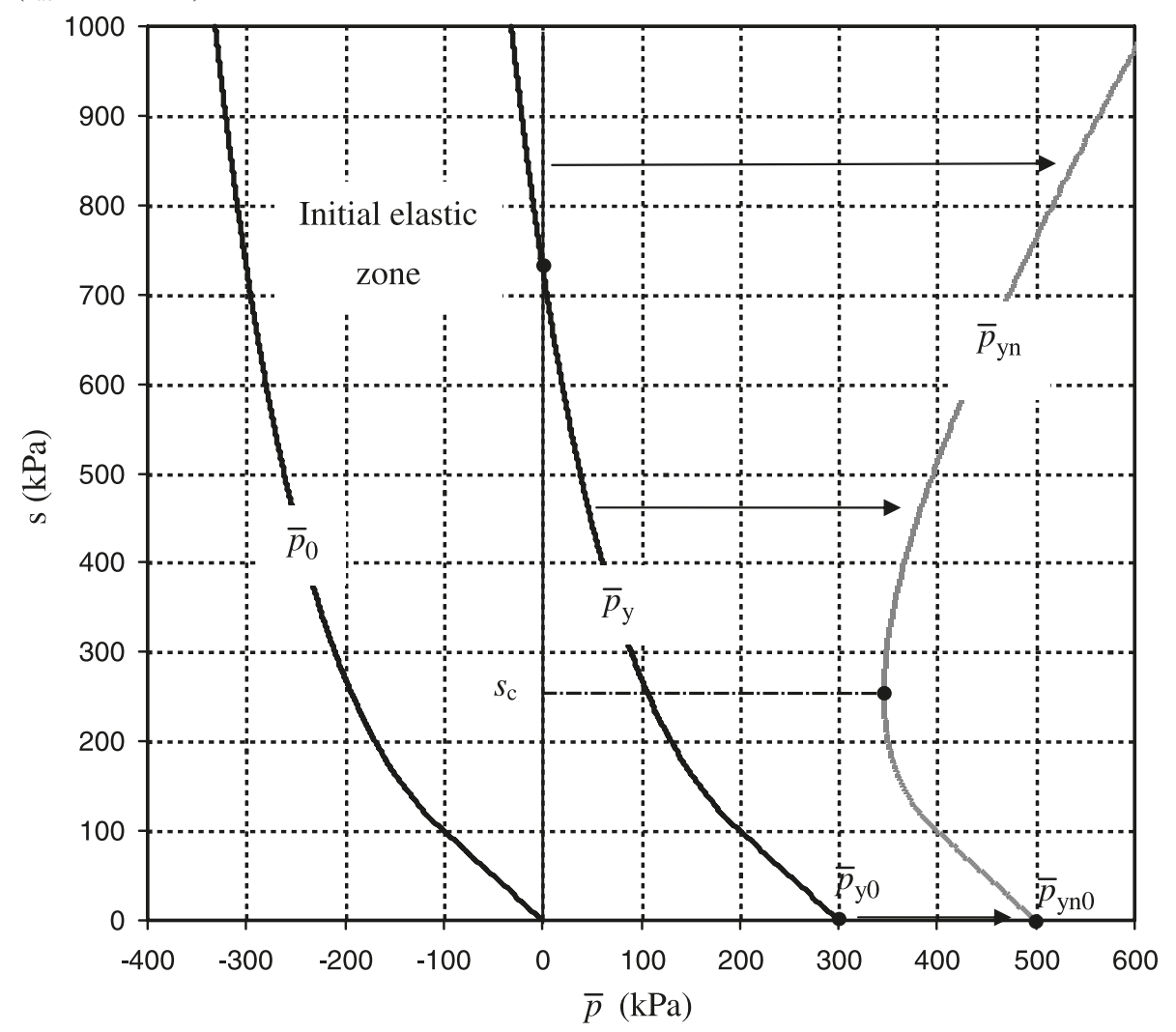

Fig. 10. Initial yield surface for a soil consolidated to $300 \mathrm{kPa}$ at zero suction and its evolution when the soil is then dried at different mean net stresses (the thin dashed line represents the initial yield surface for a soil consolidated to $500 \mathrm{kPa}$ at zero suction).

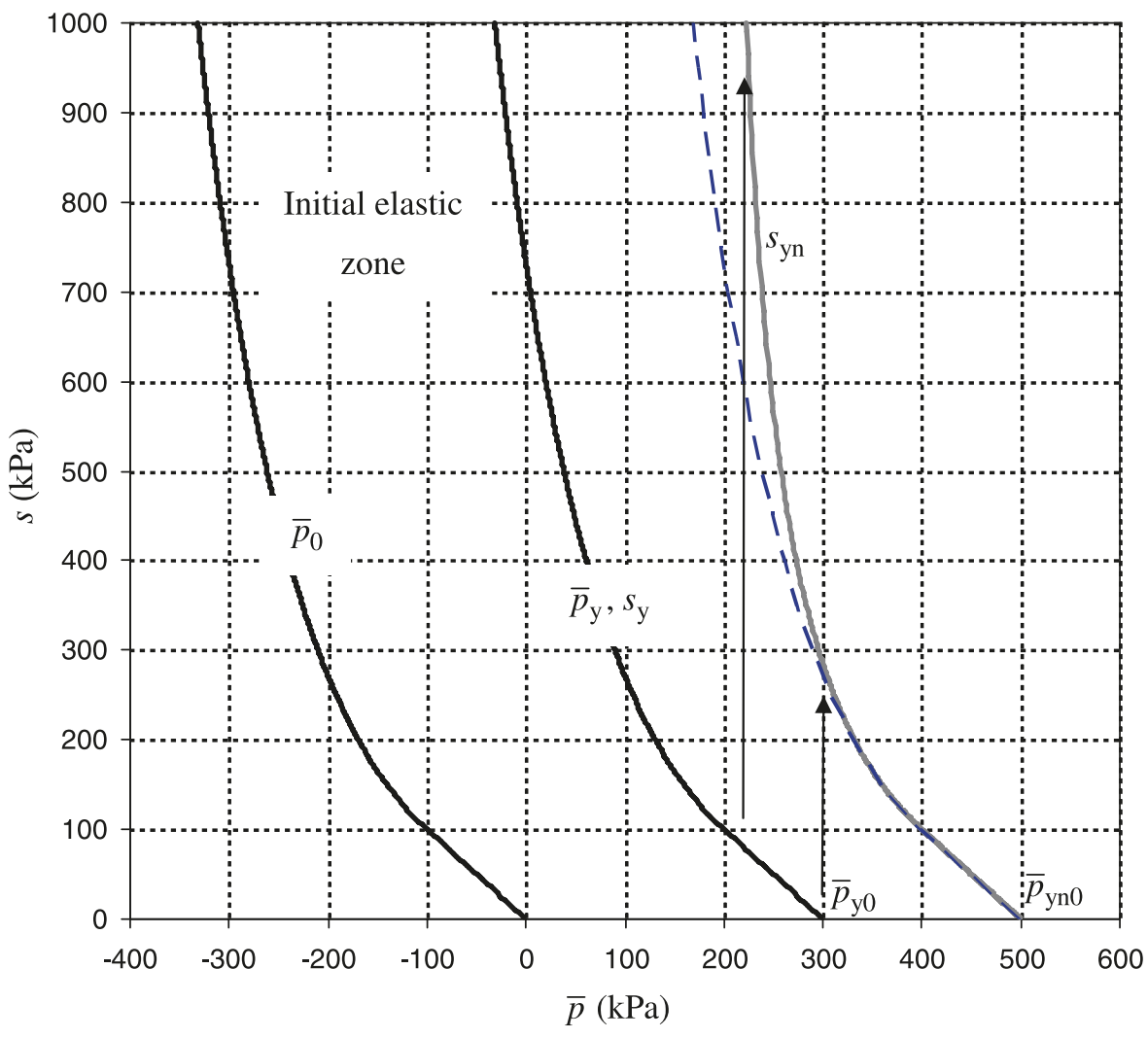




$$
\lambda_{\mathrm{ws}}= \begin{cases}0 & \mathrm{~s}<\mathrm{s}_{\mathrm{sa}} \\ \kappa_{\mathrm{ws}} & \mathrm{s}_{\mathrm{sa}} \leq \mathrm{s}<\mathrm{s}_{\mathrm{ae}} \\ \lambda_{\mathrm{ws}} & \mathrm{s} \mathrm{ae} \leq \mathrm{s}<\mathrm{s}_{\mathrm{re}} \\ \kappa_{\mathrm{ws}} & \mathrm{s} \geq \mathrm{s}_{\mathrm{re}}\end{cases}
$$

where $s_{\mathrm{ae}}$ is the air-entry value, and $s_{\mathrm{re}}$ is the residual suction (see Fig. 11).

Hysteresis in soil-water characteristics is usually considered to be too important to ignore. Therefore, a wetting curve must be added, and this curve is controlled by the water-entry value $s_{\text {we }}$ and has a similar slope, $\lambda_{\text {ws }}$ (see Fig. 11). A series of parallel lines having a slope $\kappa_{\mathrm{ws}}$ are used to represent recoverable changes in $S_{\mathrm{r}}$ between the drying (desorption) and the wetting (adsorption) curves. These curves are called "scanning curves". For the purpose of this study, the slope of the scanning curve is assumed to be identical to the slope of the drying curve for suctions below the air-entry value and suctions above the residual value. The slope of the wetting curve for suctions above the water-entry value is also assumed to be $\kappa_{\mathrm{ws}}$ (see Fig. 11). The simplifications adopted here are similar to those in the model by Wheeler et al. (2003). In the simplified model, the maximum suction that corresponds to full saturation is the saturation suction $\left(s_{\mathrm{sa}}\right)$, not the air-entry value $\left(s_{\mathrm{ae}}\right)$.

Hysteresis of soil-water characteristics can also be explained within the same framework of elastoplasticity (Wheeler et al. 2003; Sheng et al. 2004). Under such a framework, an unsaturated state always lies within the main drying and wetting curves. Drying or wetting from within the hysteresis loops will only cause recoverable water content changes until the suction reaches the main drying or wetting curve. Once soil suction reaches the main drying or wetting curve, further drying or wetting will cause irrecoverable water content changes. Therefore, the drying and wetting curves define the boundaries of recoverable water content change and are similar to the NCL. The scanning curves define the recoverable water content change and are similar to the URL. On the $\bar{p}-s$ plane, two additional boundaries can be added, representing the main drying and wetting curves, respectively (Fig. 12).

\section{Incremental stress-strain relations}

An incremental stress-strain relation can be derived for the proposed model. The plastic potential functions for yield surfaces are needed and, as a starting point, an associated flow rule can be assumed. The final incremental stressstrain relationship can be written in the following form:

$$
\left(\begin{array}{c}
\mathrm{d} \overline{\boldsymbol{\sigma}} \\
\mathrm{d} \theta
\end{array}\right)=\left(\begin{array}{cc}
\mathbf{D}^{\mathrm{ep}} & \mathbf{W}^{\mathrm{ep}} \\
\mathbf{R} & G
\end{array}\right)\left(\begin{array}{c}
\mathrm{d} \boldsymbol{\varepsilon} \\
\mathrm{d} s
\end{array}\right)
$$

where $\mathbf{D}^{\text {ep }}$ is a $6 \times 6$ matrix, $\mathbf{R}$ is a row vector of six elements, $\mathbf{W}^{\text {ep }}$ is a column vector of six elements, and $G$ is a scalar. Details of the derivation are given in Appendix B. In eq. [27], the rate of soil suction is kept on the right-hand side as the strain rate, to be consistent with the displacement finite element method where pore pressures and displacements are first solved from equilibrium and continuity equations. The incremental stress-strain relationship defined by eq. [27] can be implemented into the finite element method to solve boundary value problems. The implementation fol-
Fig. 11. Degree of saturation versus suction (dashed lines represent simplification).

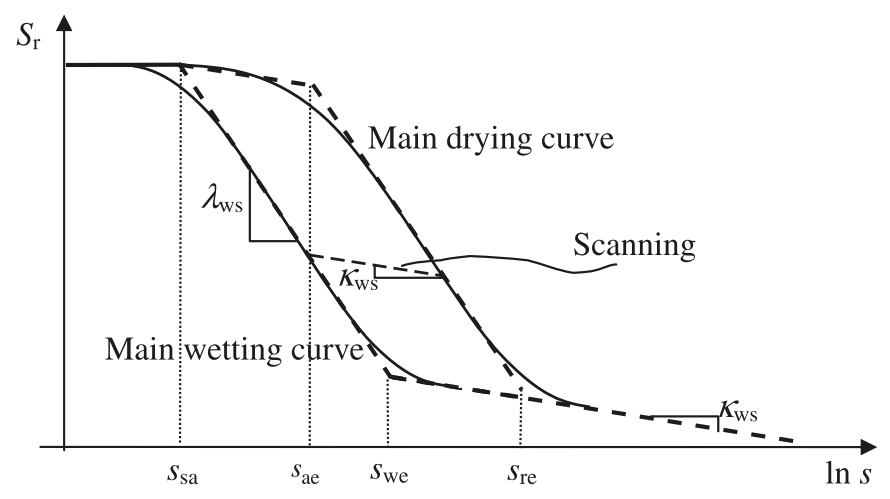

lows Sheng et al. (2000, 2003a, 2003b) and Sloan et al. (2001). Due to the nonconvexity of the yield surface on the plane of mean net stress versus suction, special techniques may be required regarding the integration of the rate equation (Sheng 2003).

\section{Numerical examples}

The model presented in this paper is referred to as the SFG model. The following material parameters have to be defined:

1. $\lambda_{\mathrm{vp}}$ : slope of the NCL for saturated soil

2. $\kappa_{\mathrm{vp}}$ : slope of the URL for saturated soil

3. $M$ : slope of the critical state line on the $q-\bar{p}$ plane

4. $\lambda_{\mathrm{ws}}$ : slope of the main drying curve

5. $\kappa_{\mathrm{ws}}$ : slope of the scanning curve

6. $s_{\mathrm{sa}}$ : saturation suction

7. $s_{\text {we }}$ : water-entry value

8. $s_{\text {re }}$ : residual suction, or residual volumetricgravimetric water content

9. $\mu$ : Poisson's ratio.

In addition, the following initial conditions need to be specified:

10. $\bar{p}_{\mathrm{y} 0}$ : initial preconsolidation pressure at zero suction

11. $e$ : initial void ratio or the specific volume.

Compared to the MCC model, the mechanical part of the SFG model has only one new parameter, that is, the saturation suction. Some of the parameters can also be functions of the suction or mean net stress. For example, the saturation suction can be a function of the mean net stress. The numerical examples presented in this section only deal with the volumetric behaviour of the model for the sake of simplicity. The shear behaviour and suction-saturation behaviour of the model are similar to existing models in the literature and will not be discussed. In addition, the numerical examples focus on the qualitative rather than quantitative predictions of the model.

\section{Initially overconsolidated saturated soil}

In the first example, let us study a soil with a low saturation suction of $10 \mathrm{kPa}$. The stress paths studied are shown in Fig. 13. The soil is first isotropically consolidated to $100 \mathrm{kPa}$ under zero suction (point $\mathrm{C}$ in Fig. 13), unloaded to a smaller mean net stress at point $\mathrm{A}$, dried to a suction of 
Fig. 12. Elastic zone enclosed by the yield surface and the drying and wetting surfaces.

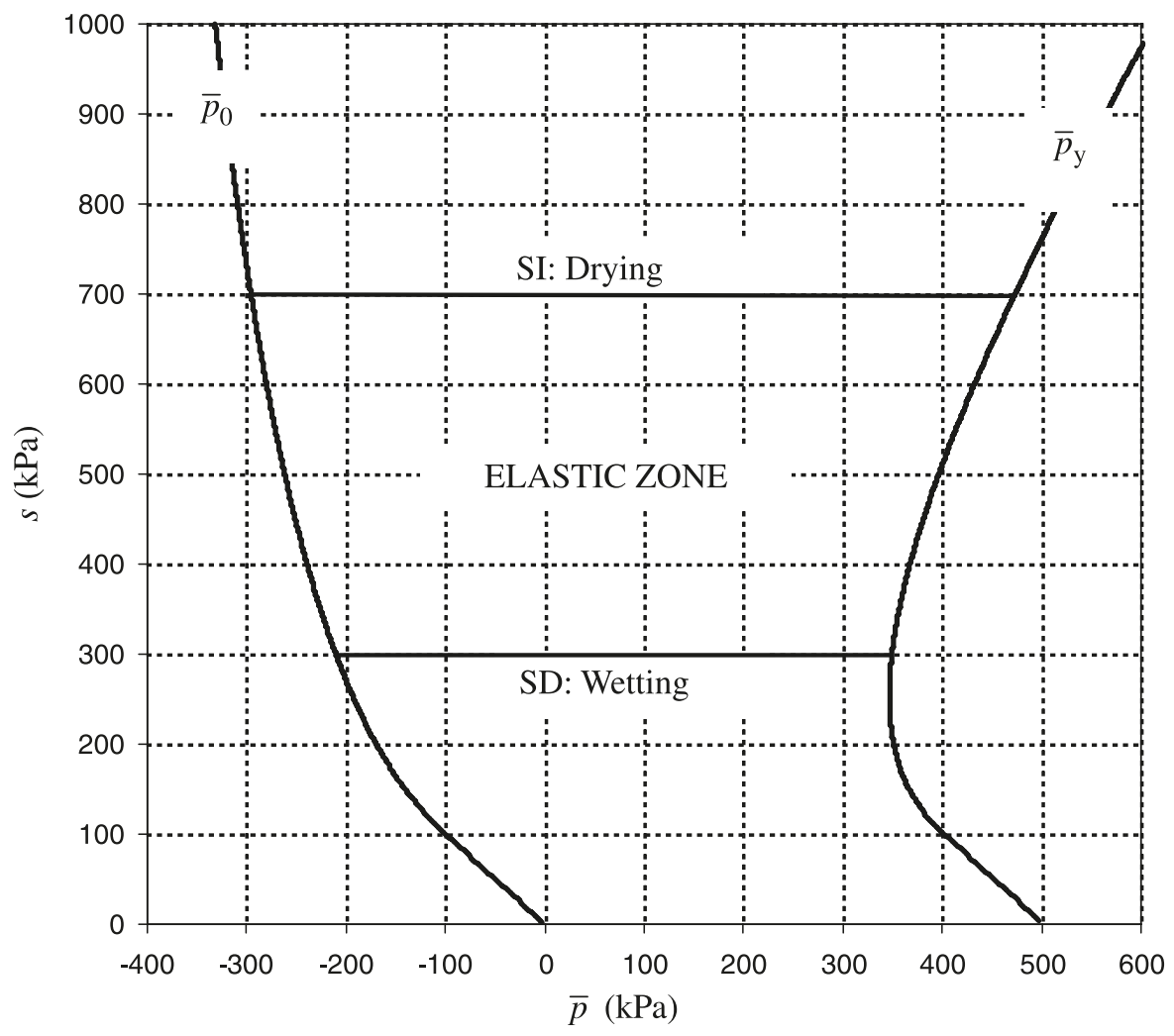

$300 \mathrm{kPa}$ (point $\mathrm{B}$ ), then isotropically loaded to $200 \mathrm{kPa}$ (point D), and finally wetted to zero suction at the constant mean net stress of $200 \mathrm{kPa}$ (point E). The mean net stress at point $\mathrm{A}$ is assumed to be $1 \mathrm{kPa}$. The initial yield surface of the soil at point $\mathrm{A}$ is then given by eq. [12] or

$$
\overline{\mathrm{p}}_{\mathrm{yA}}= \begin{cases}100-\mathrm{s} & \mathrm{s}<10 \mathrm{kPa} \\ 90-11 \cdot \ln \left(\frac{\mathrm{s}+1}{11}\right) & \mathrm{s} \geq 10 \mathrm{kPa}\end{cases}
$$

This yield surface is shown in Fig. 13. It shows that the initial yield stress decreases continuously with increasing suction. The drying path from point A to point B will only cause elastic deformation, as the path is inside the yield surface. However, the loading path from point $\mathrm{B}$ to point $\mathrm{D}$ will cross the initial yield surface at point $\mathrm{B}^{\prime}$ and causes plastic volume change and hardening. The yield surface at an intermediate point $\mathrm{D}^{\prime}$, where $\bar{p}=100 \mathrm{kPa}$, can be found using eq. [18], leading to

$$
\overline{\mathrm{y}}_{\mathrm{yD}^{\prime}}=\left\{\begin{array}{l}
113.12-\mathrm{s} \\
\frac{113.12}{100}\left[90+\mathrm{s}-11 \cdot \ln \left(\frac{\mathrm{s}+1}{11}\right)\right]-\mathrm{s} \quad \mathrm{s} \geq 10 \mathrm{kPa}
\end{array}\right.
$$

where the number 113.12 is obtained by solving eq. [18] with $s=300 \mathrm{kPa}$ and $\bar{p}_{\mathrm{yn}}=100 \mathrm{kPa}$. The yield stress on the new yield surface $\bar{p}_{\mathrm{yD}^{\prime}}$ no longer decreases continuously with increasing suction. Rather, it reaches a minimum value at a suction of

$$
\mathrm{s}_{\mathrm{cD}^{\prime}}=\frac{11 \times 113.12}{113.12-100}-1=93.82 \mathrm{kPa}
$$

and then increases with increasing suction. The shape of the yield surface $\bar{p}_{\mathrm{yD}^{\prime}}$ indicates that, if the soil were wetted at the intermediate point D', some volume collapse would occur. Such collapse behaviour is supported by experimental data (e.g., by Sun et al. 2007b).

Continuing compression from point $\mathrm{D}^{\prime}$ to point $\mathrm{D}$ leads to a new yield surface:

$$
\overline{\mathrm{p}}_{\mathrm{yD}}=\left\{\begin{array}{l}
141.4-\mathrm{s} \\
\frac{141.4}{100}\left[90+\mathrm{s}-11 \cdot \ln \left(\frac{\mathrm{s}+1}{11}\right)\right]-\mathrm{s} \quad \mathrm{s} \geq 10 \mathrm{kPa}
\end{array}\right.
$$


Fig. 13. Stress path and yield surfaces for example 1: drying at a mean net stress of $1 \mathrm{kPa}\left(s_{\mathrm{ae}}=10 \mathrm{kPa}\right)$.

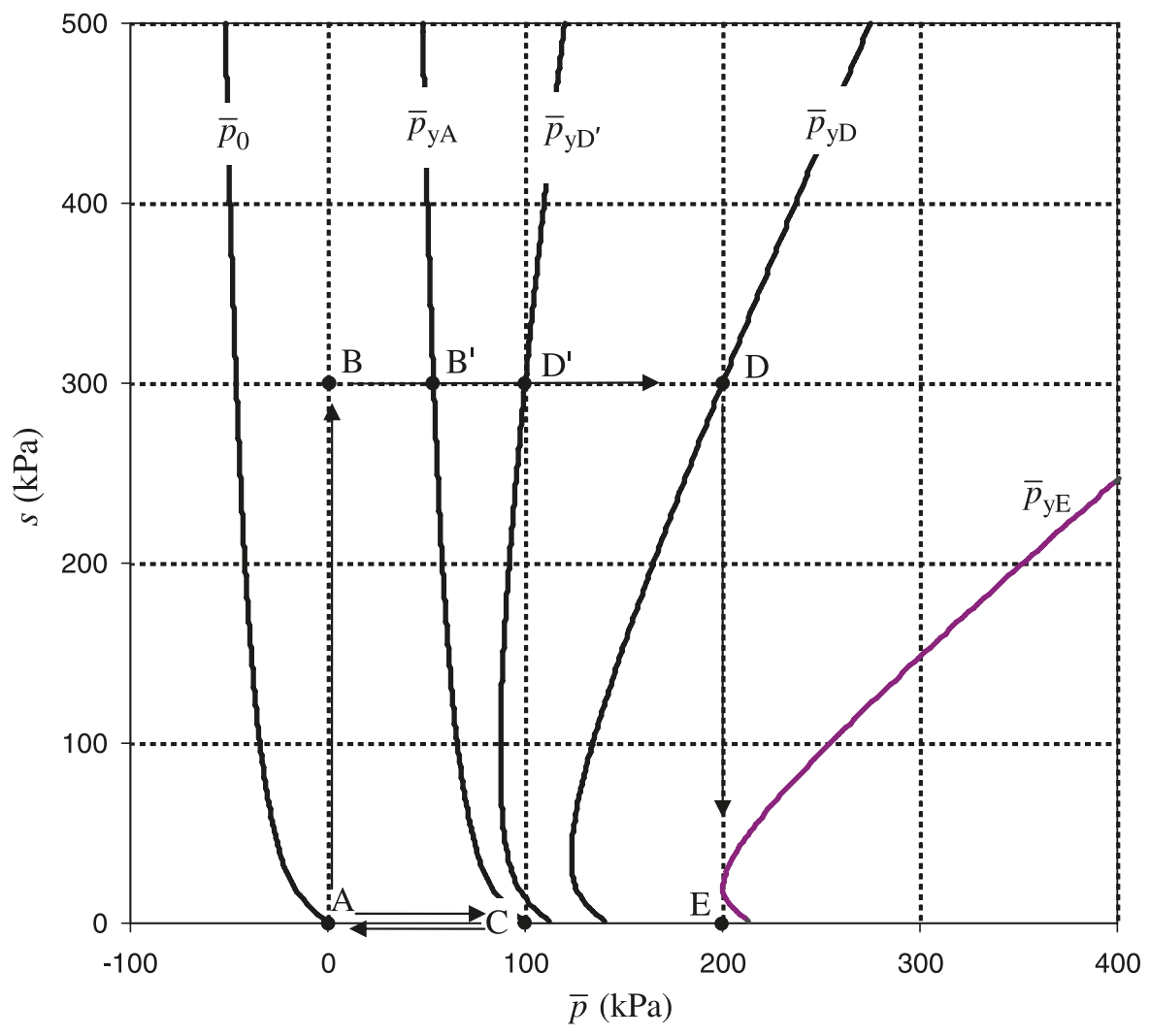

where the number 141.4 is obtained by solving eq. [18] with $s=300 \mathrm{kPa}$ and $\bar{p}_{\text {yn }}=200 \mathrm{kPa}$. The new yield surface at point $\mathrm{D}$ is also shown in Fig. 13. This yield surface takes a similar shape to the loading-collapse yield surface in the BBM. The new minimum collapsible suction becomes

$$
\mathrm{s}_{\mathrm{CD}^{\prime}}=\frac{11 \times 141.4}{141.4-100}-1=36.57 \mathrm{kPa}
$$

This value is smaller than the previous value at point $\mathrm{D}^{\prime}$. It can be shown that the minimum collapsible suction approaches the saturation suction when the mean net stress approaches infinity.

If the soil is wetted from point $\mathrm{D}$ to point $\mathrm{E}$, the stress path will first cause elastoplastic volume change and then only elastic volume change. However, the hardening law can no longer be solved analytically. The numerical solution of the yield surface at point $\mathrm{E}$ is shown in Fig. 13. Point E corresponds to the new preconsolidation stress at zero suction.

The volume change during the stress path ABDE is shown in Fig. 14. The material parameters used to obtain the results are given below

$$
\begin{aligned}
\lambda_{\mathrm{vp}}=0.1, \quad \kappa_{\mathrm{vp}}=0.02, \quad \mathrm{~s}_{\mathrm{sa}} & =10 \mathrm{kPa}, \\
e_{\mathrm{A}} & =0.7, \quad \bar{p}_{\text {уо }}=100 \mathrm{kPa}
\end{aligned}
$$

where $e_{\mathrm{A}}$ is the initial void ratio at point A. Figure $14 a$ shows the void ratio changes against mean net stress. The volume change from point $\mathrm{A}$ to $\mathrm{B}$ is due to the elastic shrinkage during drying path $\mathrm{AB}$. The volume change from
$\mathrm{B}$ to $\mathrm{B}^{\prime}$ follows the URL at a suction level of $300 \mathrm{kPa}$. It should be noted that the slope of the URL depends on the suction level. Figure $14 a$ shows that the line between B and $\mathrm{B}^{\prime}$ is much flatter than the URL at zero suction. The volume change between $\mathrm{B}^{\prime}$ and $\mathrm{D}$ follows the NCL at a suction level of $300 \mathrm{kPa}$. Again, the line between $\mathrm{B}^{\prime}$ and D is much flatter than the NCL at zero suction. The volume change from $\mathrm{D}$ to $\mathrm{E}$ is due to wetting-induced collapse. Such a volume collapse can also be predicted by the BBM as well as by other existing models. Figure $14 b$ shows the volume changes against soil suction. It is noted that the end portion of the stress path DE causes a small elastic swelling.

In a summary of this example, it is noted that the SFG model works differently from the BBM (Alonso et al. 1990), even though both models predict the volume collapse during the wetting path DE (Fig. 14a). The plastic volume change between point $\mathrm{B}$ and point $\mathrm{D}$ is mostly neglected in the BBM. The SFG model can predict the volume collapse at a lower mean net stress (point $\mathrm{D}^{\prime}$ in Fig. 13). In addition, the model is able to predict some plastic volume change caused by drying from point $A$ to point $B$ if the mean net stress at point $\mathrm{A}$ is sufficiently high.

\section{Initially slurry soil}

In the second example, let us study a slurry soil that has not quite been consolidated. Because logarithmic functions such as those in eqs. [3] and [9] are not defined at zero mean net stress and zero suction, the soil is assumed to be consolidated to $1 \mathrm{kPa}$ at zero soil suction. The soil is as- 
Fig. 14. Volume change for example 1 , drying at a mean net stress of $1 \mathrm{kPa}\left(\lambda_{\mathrm{vp}}=0.1, \kappa_{\mathrm{vp}}=0.02, s_{\mathrm{ae}}=10 \mathrm{kPa}\right)$. (a) Void ratio versus mean net stress. (b) Void ratio versus suction.
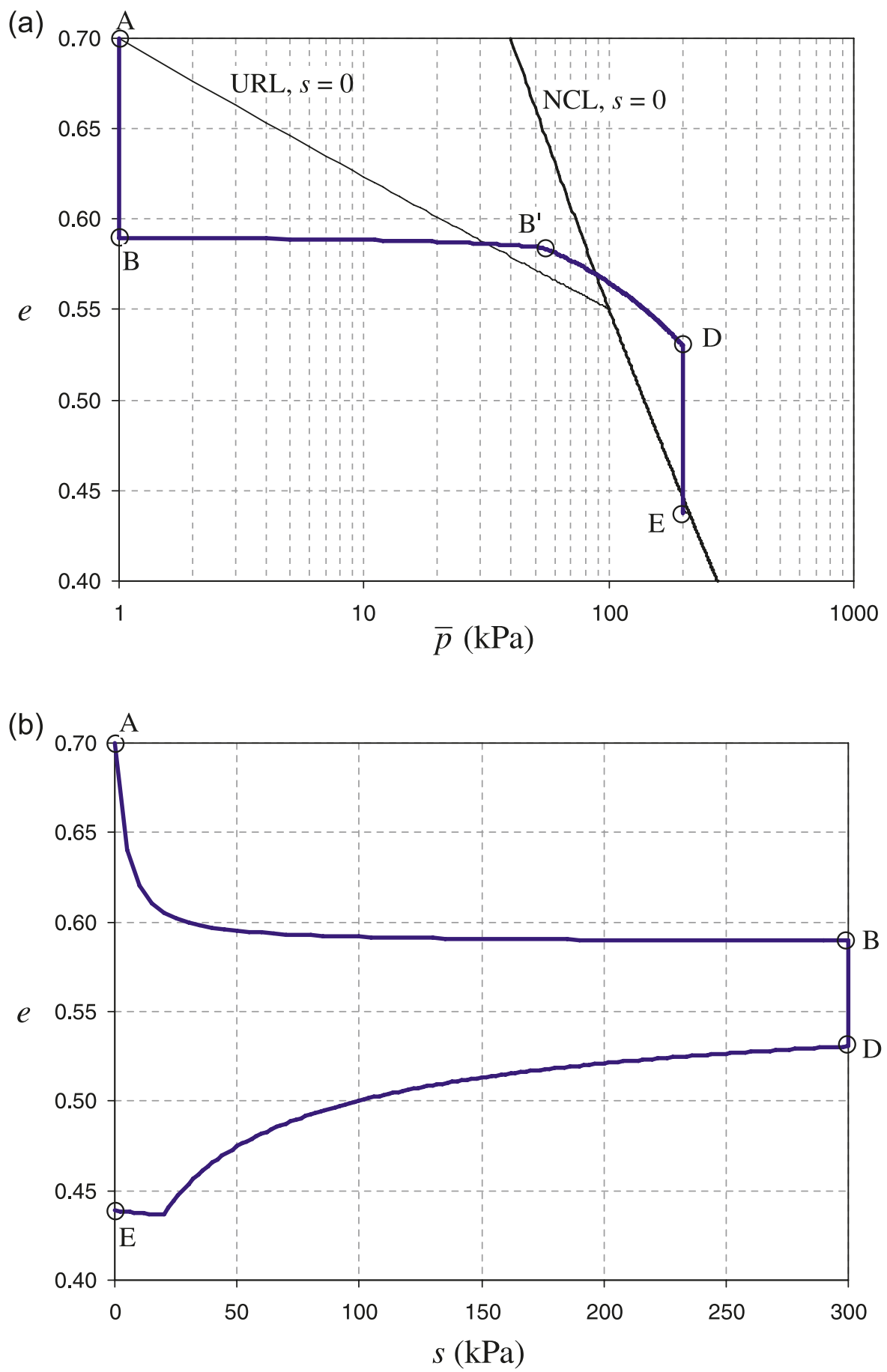

sumed to have a relatively high saturation suction of $500 \mathrm{kPa}$. The projection of the initial yield surface onto the $\bar{p}-s$ plane is then

$$
s_{\mathrm{y}}= \begin{cases}501 \cdot \exp \left(\frac{-499-\bar{p}}{501}\right)-1 & \bar{p} \leq-499 \mathrm{kPa} \\ 1-\bar{p} & \bar{p}>-499 \mathrm{kPa}\end{cases}
$$

This initial yield surface is very close to the $\bar{p}_{0}$ curve in
Fig. 15, meaning that the soil has little shear strength or a very small elastic region at zero mean stress and zero suction. Indeed, if the slurry soil were not consolidated at all, the initial yield surface would be a single point at the origin $\left(\bar{p}_{\mathrm{y}}=\bar{p}_{0}\right)$.

The slurry soil is first dried to a suction level at point B (Fig. 15) under a mean net stress of $1 \mathrm{kPa}$ and then isotropically compressed to a mean net stress at point $\mathrm{D}$ while the suction is kept constant. The yield surface at point B is defined by eq. [23] 
Fig. 15. Stress path and yield surfaces for example 2: drying and loading of slurry soil $\left(s_{\mathrm{ae}}=500 \mathrm{kPa}\right)$.

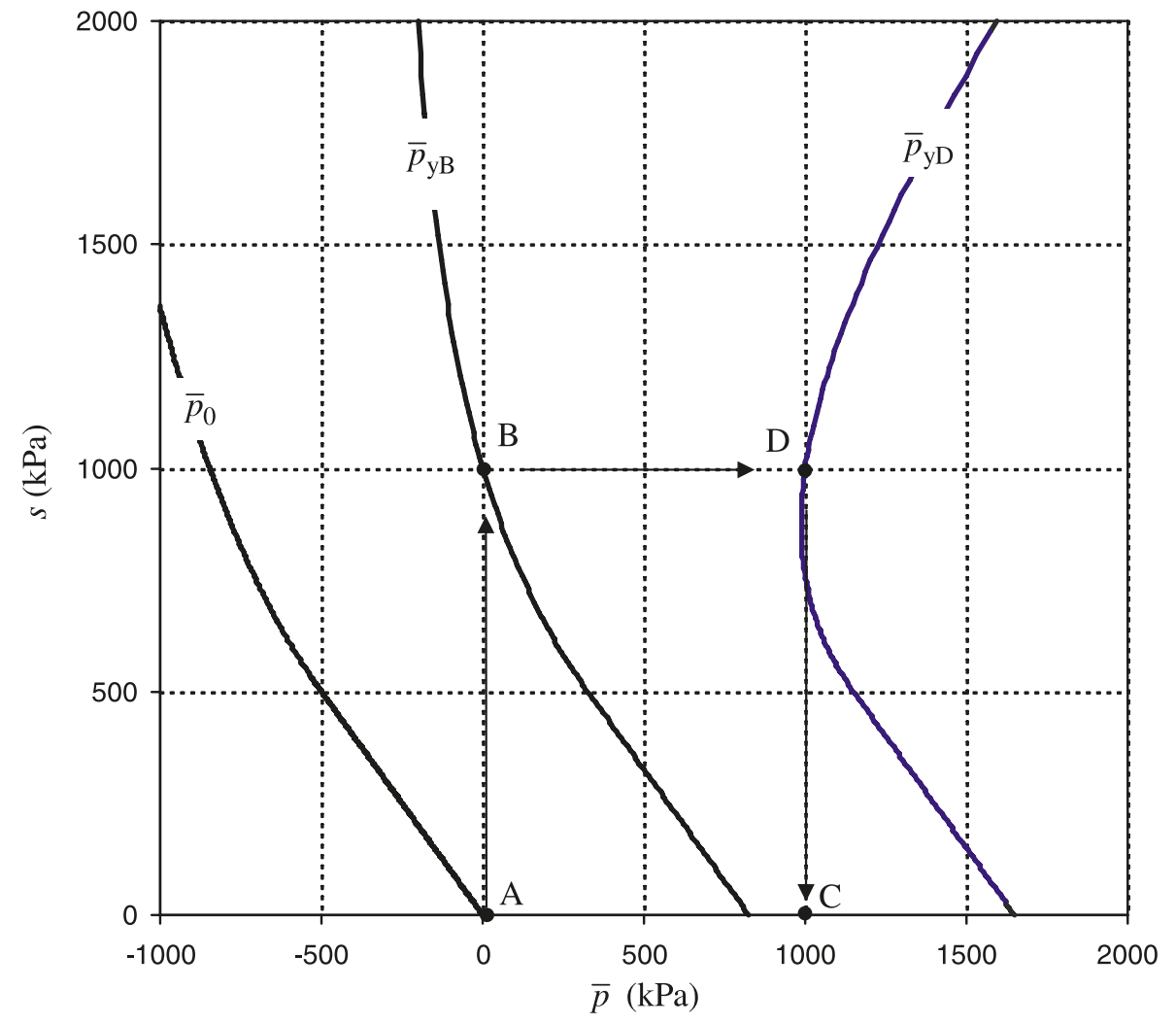

Fig. 16. Normal compression lines at different suctions (slurry soil, $N=3, \lambda_{\mathrm{vp}}=0.1, s_{\mathrm{ae}}=500 \mathrm{kPa}$ ).

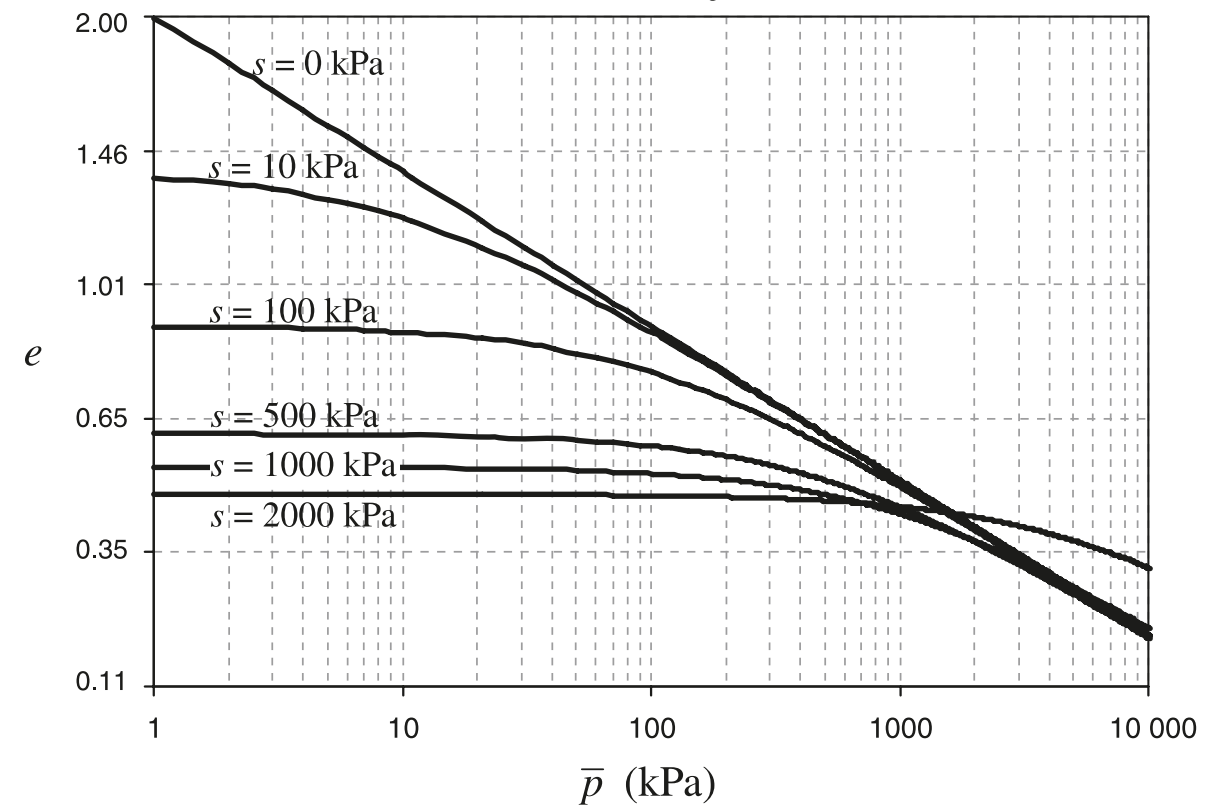

[29] $\quad s_{\mathrm{yB}}=\left\{\begin{array}{ll}\frac{B \bar{p}-1}{1-B} & \bar{p}_{\mathrm{y} 0}^{\mathrm{B}}-500 \geq \bar{p}>-499 \\ \bar{p}_{\mathrm{y} 0}^{\mathrm{B}}-\bar{p} & \bar{p}>\bar{p}_{\mathrm{y} 0}^{\mathrm{B}}-500\end{array} \quad B=\left(\frac{\bar{p}_{\mathrm{y} 0}^{\mathrm{B}}}{\bar{p}+500}\right)^{\frac{\bar{p}-1}{501}} \frac{501}{500+\bar{p}}\right.$

where the intercept $\bar{p}_{\mathrm{y} 0}^{\mathrm{B}}$ can be found by setting $s_{\mathrm{y}}=s_{\mathrm{B}}$ and $\bar{p}=1 \mathrm{kPa}$ into eq. [24] 
Fig. 17. Volume and water content changes (slurry soil, $s_{\mathrm{ae}}=500 \mathrm{kPa}, N=3, \lambda_{\mathrm{vp}}=0.1, \lambda_{\mathrm{vs}}=0.4, \kappa_{\mathrm{vs}}=0.0, s_{\mathrm{re}}=5000 \mathrm{kPa}$ ). $(a) \mathrm{Volume}$ change following stress path ABD. (b) Water content change following stress path ABD.
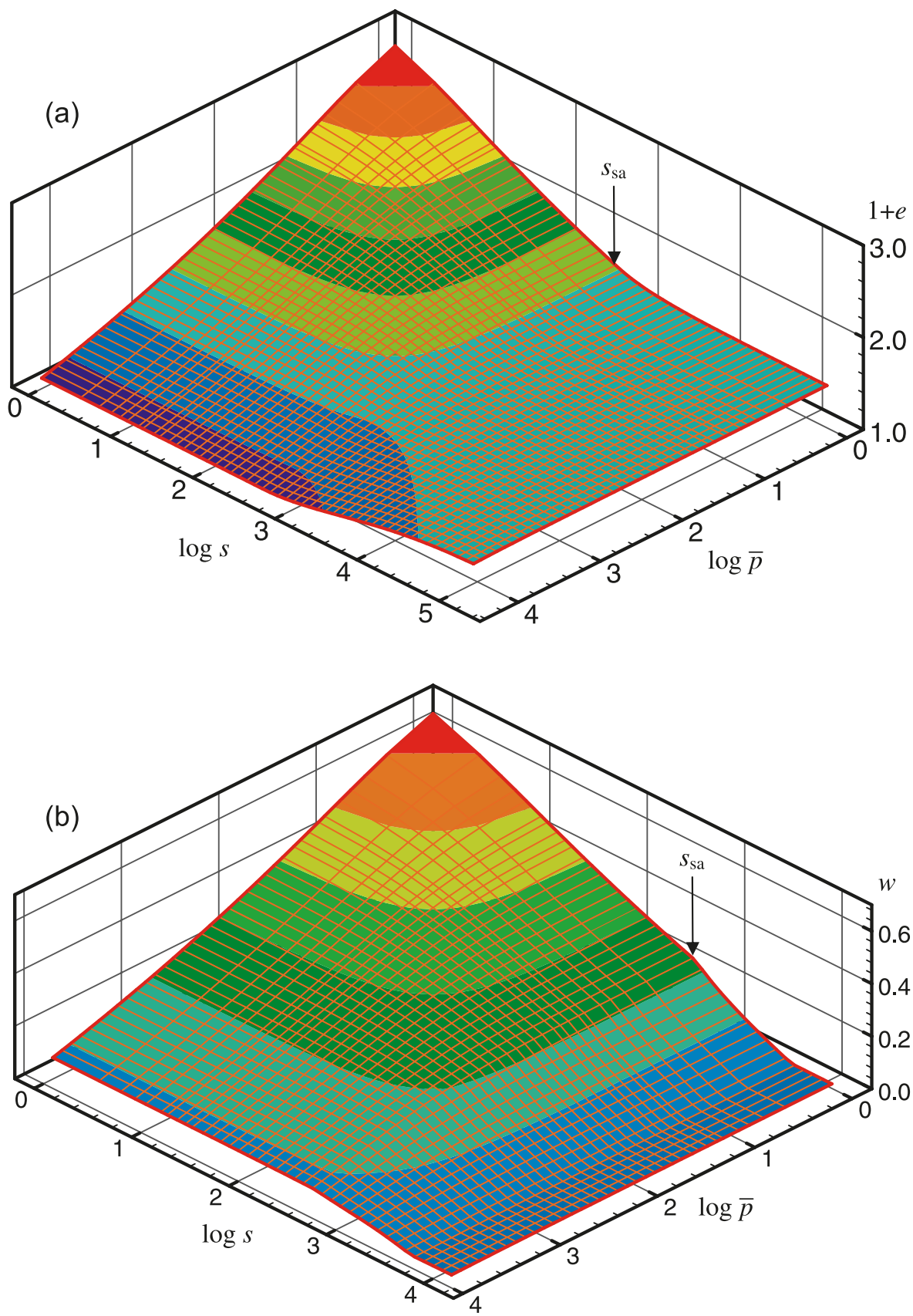

$$
\overline{\mathrm{p}}_{\mathrm{y} 0}^{\mathrm{B}}=501 \cdot \exp \left(1-\frac{500+1}{\mathrm{~s}_{\mathrm{B}}+1}\right)
$$

and $s_{\mathrm{B}}$ is the suction at point $\mathrm{B}$. The yield surface at point $\mathrm{D}$ is then given by the following equation:

$$
\bar{p}_{\mathrm{yD}}=\frac{\bar{p}_{\mathrm{y} 0}^{\mathrm{D}}}{\bar{p}_{\mathrm{y} 0}^{\mathrm{B}}}\left(\bar{p}_{\mathrm{yB}}+s\right)-s
$$

where $\bar{p}_{\mathrm{yB}}$ is defined implicitly in eq. [29] as a function of the suction, and $\bar{p}_{\mathrm{y} 0}^{\mathrm{D}}$ can be found by setting the mean net stress and the suction at point $\mathrm{D}$ in eq. [30].

The yield surfaces given by eqs. [29] and [30] are plotted in Fig. 15 for $s_{\mathrm{B}}=1000 \mathrm{kPa}$. It is noted that, if the soil is wetted from point $\mathrm{D}$ to point $\mathrm{C}$, a very small amount of volume collapse is followed by a larger amount of elastic swelling. The total volume change between $\mathrm{D}$ and $\mathrm{C}$ is then an increase, which is further confirmed by the void ratio plots in Fig. 16. The volumetric behaviour shown in Fig. 16 is similar to the experimental results reported by Fredlund (1964) for Regina clay. The suction and mean net stress levels required to initiate a significant volume collapse are very high. As shown in Fig. 16, a significant collapse occurs when the suction and the mean net stress at point $\mathrm{D}$ are both above $2000 \mathrm{kPa}$.

Figure 17 shows the 3D surfaces for the volume and water content changes in stress path $\mathrm{ABD}$. The material parameters used to obtain the plots are: 
Fig. 18. Initial yield surface for the soil before compaction $\left(s_{\mathrm{sa}}=0 \mathrm{kPa}\right)$.

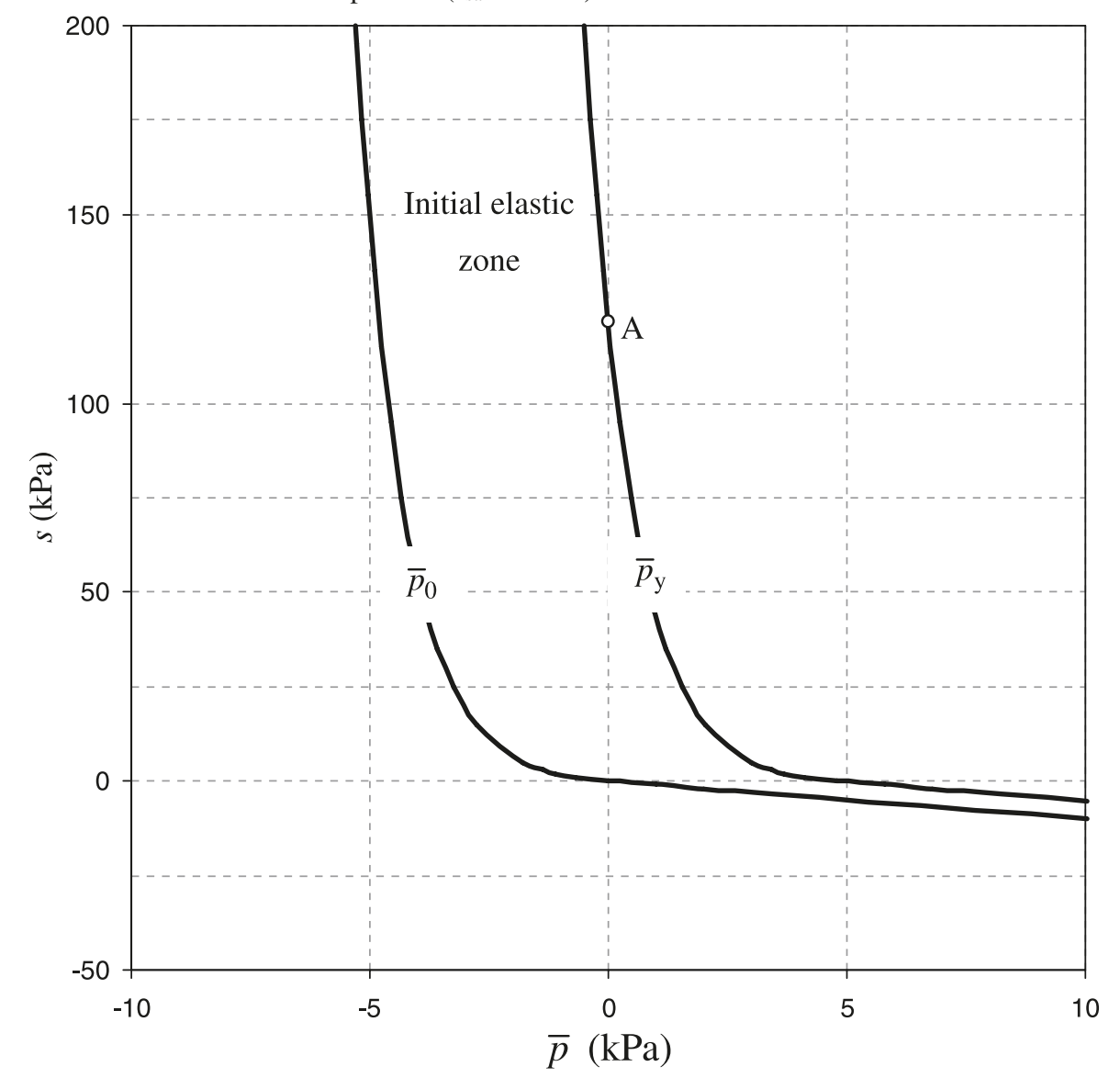

$\mathrm{s}_{\mathrm{sa}}=500 \mathrm{kPa}, \quad \mathrm{N}=3, \quad \lambda_{\mathrm{vp}}=0.1, \quad \lambda_{\mathrm{vs}}=0.4$,

$$
\kappa_{\mathrm{vs}}=0.0, \quad s_{\mathrm{re}}=5000 \mathrm{kPa}, \quad \rho_{\mathrm{s}}=2.7 \mathrm{t} / \mathrm{m}^{3}
$$

where $s_{\mathrm{re}}$ is the residual suction, and $\rho_{\mathrm{s}}$ is the specific density of soil solids (note: $1 \mathrm{t}=1000 \mathrm{~kg}$ ). The specific density $\rho_{\mathrm{s}}$ is only used to generate the gravimetric water content, which is usually used in soil mechanics instead of the volumetric water content..

The contours of specific volume in Fig. $17 a$ look quite different from the yield surface shown in Fig. 15, because of the double $\log$ arithmic axes $(\log \bar{p}-\log s)$. Figure $17 b$ shows the predicted changes in gravimetric water content. The predicted water content continues to decrease as the soil suction increases above the saturation suction, even at a higher rate than that below the saturation suction. The reason for this behaviour can be observed from the following equation:

$$
\mathrm{w}=\mathrm{S}_{\mathrm{r}} \mathrm{e} / \rho_{\mathrm{s}}=\theta(1+\mathrm{e}) / \rho_{\mathrm{s}}
$$

where $w$ is the gravimetric water content, and $S_{\mathrm{r}}$ is the degree of saturation. Increasing suction below the saturation suction only changes the void ratio $e$, because the degree of saturation remains constant. Once the suction is above the saturation suction, increasing the suction further reduces both $S_{\mathrm{r}}$ and $e$. Therefore, increasing suction above the saturation suction becomes even more effective in expelling water. The decrease in water content continues until the residual suction is reached. The SFG model well captures this type of behaviour.
To summarize this example, existing models are less flexible in modelling the behaviour of soils that are initially in a slurry condition. They usually have to assume an apparent preconsolidation stress for handling the initially flat portions of the NCLs at suctions larger than zero. As such, the loading-collapse yield surface cannot predict the plastic deformation associated with initial drying. On the other hand, the SFG model accommodates the initial drying and its effects on the soil compressibility in a natural way and can predict the volumetric behaviour at high suctions without adopting an apparent preconsolidation stress.

\section{Initially unsaturated soil}

This example illustrates the simulation of an initially unsaturated soil using the SFG model. The compacted Pearl clay, an industrial product whose collapse behaviour has been studied by Sun et al. (2004, 2007b), is used for the example. The SFG model is used to model one type of the tests used in Sun et al. (2007b). Air-dried soil particles are mixed with the required amount of water to reach a specified water content. The initial suction of the precompacted soil is $120 \mathrm{kPa}$. The soil is then compacted under a static compaction pressure of $300 \mathrm{kPa}$, to reach a specific density or void ratio $(e=1.28)$. The compacted soil is tested in a controlled-suction triaxial cell. In the triaxial cell, the soil specimen is first dried to a suction of $147 \mathrm{kPa}$ and then isotropically compressed to different mean net stresses before it is finally wetted to zero suction. 
Fig. 19. Yield surface for the compacted soil and stress paths during isotropic compression and wetting $\left(s_{\mathrm{sa}}=20 \mathrm{kPa}\right)$.

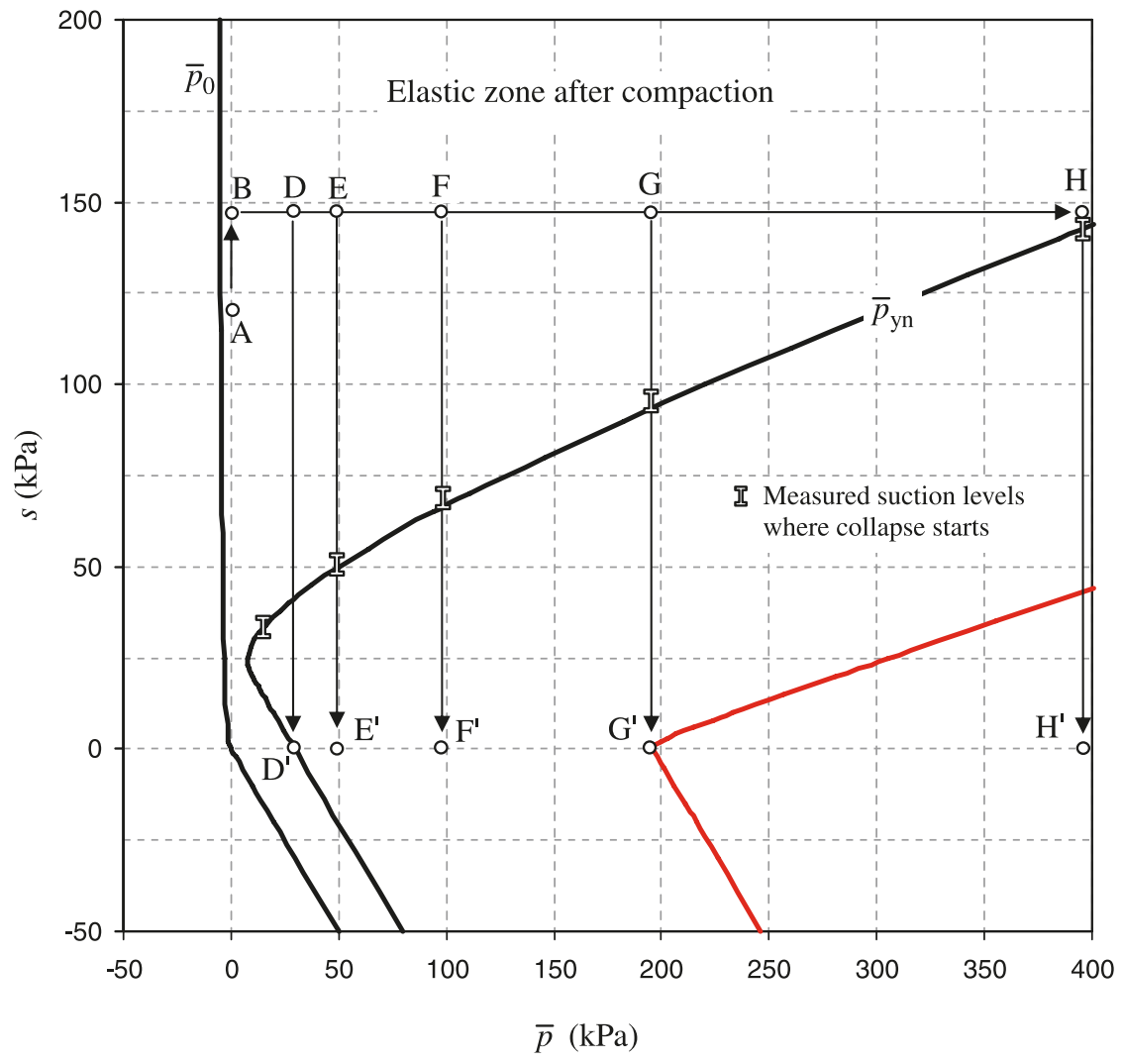

The saturation suction of the soil is zero under zero mean net stress. The initial elastic zone for the precompacted soil

is banded by $\bar{p}_{0}$ and $\bar{p}_{\mathrm{y}}$ on the $\bar{p}-s$ plane, with $\bar{p}_{\mathrm{y}}$ and $\bar{p}_{0}$ given by eqs. [12] and [13], respectively

$$
\overline{\mathrm{p}}_{\mathrm{y}}=\left\{\begin{array}{ll}
4.8-\mathrm{s} & \mathrm{s}<0 \\
4.8-\ln (\mathrm{s}+1) & \mathrm{s} \geq 0
\end{array} \quad \overline{\mathrm{p}}_{0}= \begin{cases}-\mathrm{s} & \mathrm{s}<0 \\
-\ln (\mathrm{s}+1) & \mathrm{s} \geq 0\end{cases}\right.
$$

where the number 4.8 is obtained by inserting $s=120 \mathrm{kPa}$ and $\bar{p}_{\mathrm{y}}=0$ into eq. [12]. These two curves are shown in Fig. 18 .

The compaction process can be approximated by an in-

crease in the mean net stress under a constant suction. A complication is that the saturation suction of the soil increases to $20 \mathrm{kPa}$ at mean net stresses above $200 \mathrm{kPa}$, according to the soil-water characteristic curves of Sun et al. (2007b). The yield surface for the compacted soil can then be approximated from eq. [18], leading to

$$
\overline{\mathrm{p}}_{\mathrm{yn}}= \begin{cases}29.7-\mathrm{s} & \mathrm{s}<20 \mathrm{kPa} \\ \frac{29.7}{4.8}\left(4.8+\mathrm{s}-20-21 \cdot \ln \frac{\mathrm{s}+1}{21}\right)-\mathrm{s} \quad \mathrm{s} \geq 20 \mathrm{kPa}\end{cases}
$$

where the number 29.7 is obtained by inserting $s=120 \mathrm{kPa}$ and $\bar{p}_{\mathrm{yn}}=300 \mathrm{kPa}$ into eq. [18]. The yield surface, $\bar{p}_{\mathrm{yn}}$, for the compacted soil is plotted in Fig. 18. The initial stress state for the compacted soil in the triaxial cell is at point A in Fig. 18. A suction of $147 \mathrm{kPa}$ is imposed on the soil specimen (point B in Fig. 18) before it is isotropically compressed to different mean net stresses (points D, E, F, and $G$ in Fig. 18). The soil is finally wetted under constant mean net stresses to zero suction (point $\mathrm{D}^{\prime}, \mathrm{E}^{\prime}, \mathrm{F}^{\prime}$, and $\mathrm{G}^{\prime}$ in Fig. 18). Figure 19 also shows the final yield surface when the soil is wetted to point $\mathrm{F}^{\prime}(\bar{p}=196 \mathrm{kPa})$, where the saturation suction is assumed to be zero.

The measured suction levels where collapse starts to occur during the final wetting paths are also shown in Fig. 18. These measured data agree well with the yield surface $\bar{p}_{\text {yn }}$. For example, volume collapse was observed to occur at a suction around $35 \mathrm{kPa}$ when the soil is wetted at $\bar{p}=20 \mathrm{kPa}$. The predicted volume changes are shown in Fig. 19. The material parameters used in the prediction are: 
Fig. 20. Predicted volume collapse during the final wetting paths (experimental results of Sun et al. 2007b shown in the lower left corner).

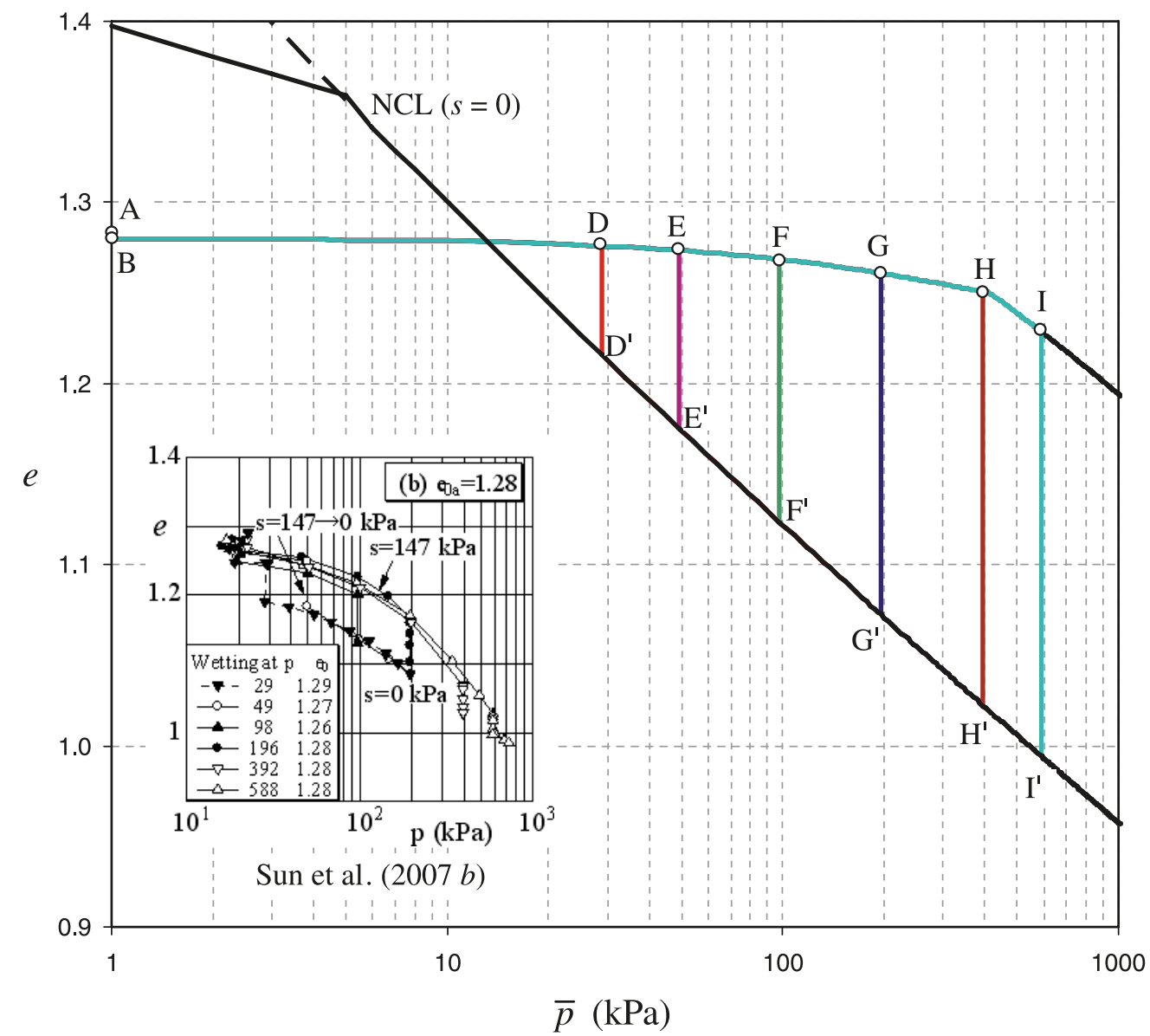

$\lambda_{\mathrm{vp}}=0.035$

$\kappa_{\mathrm{vp}}=0.01$

$e_{\mathrm{A}}=1.28$

$s_{\mathrm{sa}}=0$ when $\bar{p}<200 \mathrm{kPa}$

$s_{\mathrm{sa}}=20 \mathrm{kPa}$ when $\bar{p} \geq 200 \mathrm{kPa}$

where $e_{\mathrm{A}}$ is the void ratio of the compacted soil sample (point A). The slope of the NCL, $\lambda_{\mathrm{vp}}$, is back-estimated from experimental data. The slope of the URL, $\kappa_{\mathrm{vp}}$, is assumed. The measured collapse volume seems to have a maximum value at a mean net stress of around $100 \mathrm{kPa}$. On the other hand, the predicted collapse volume approaches a constant value at mean net stresses larger than $414 \mathrm{kPa}$. The discrepancy between the predicted and measured results is mainly due to the Cam Clay elastoplasticity, where a stress path inside the current yield surface causes only elastic deformation. In addition, the simplistic nature of the constant $\lambda_{\mathrm{vp}}$ used in the proposed model also contributes somewhat to the discrepancy. Indeed, if $\lambda_{\mathrm{vp}}$ is assumed to increase with increasing suction, the collapse strain would then reach a maximum at intermediate stress levels. The void ratio changes during the wetting paths are shown in Fig. 20. The curves for stress paths $\mathrm{HH}^{\prime}$ and $\mathrm{II}^{\prime}$ are obtained using a saturation suction of $20 \mathrm{kPa}$, while the other curves are obtained using a zero saturation suction. The predicted volume changes during the wetting path are shown in Fig. 21.
This example shows that the SFG model can model a soil that is initially unsaturated. It should be noted that the actual compaction process is more complex than the simulation shown here. Therefore, this example only serves as an illustration of qualitative modelling of soils that are initially unsaturated, in line with the qualitative nature of other examples in this paper.

\section{Conclusions}

This paper presents a new elastoplastic model for unsaturated soils using independent stress state variables. In so doing, it addresses some previously unanswered questions. These questions relate to the change of the yield stress with suction and the smooth curvature of the NCLs at constant soil suctions. A new volume-stress-suction relationship is proposed to model the volume changes caused by independent changes in stresses and soil suction. The MCC model is used as the base model for saturated states, and it is generalized to unsaturated states through a smooth transition. The projection of the yield surface on the plane of mean net stress versus suction is derived. The evolution of the yield surface under different stress paths is illustrated. The presented model also accommodates hysteresis associated with wetting and drying.

It is shown that the yield stress initially decreases with increasing suction below the saturation suction, but may in- 
Fig. 21. Predicted volume collapse during the final wetting paths, void ratio versus suction.

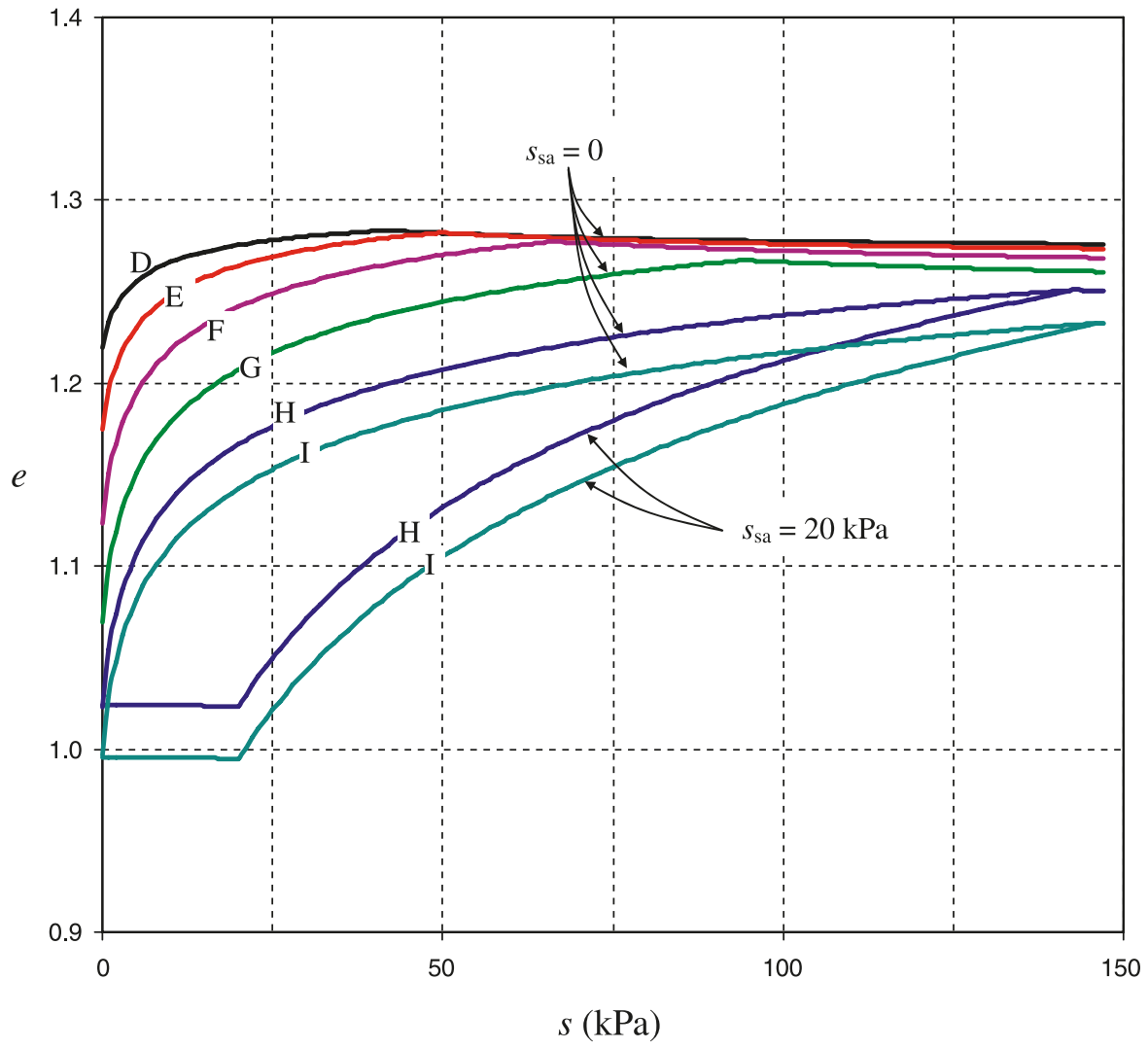

crease or decrease for suctions above the saturation suction, depending on the stress path. The yield stress for a soil that has never been overconsolidated at suctions above zero always decreases with increasing suction. However, compaction or consolidation of the soil at suctions above zero can change the shape of the yield surface. It also is shown that the smooth curvature of the NCLs at constant suctions is a natural result of the proposed volume-stress-suction relationship. The variation of the soil compressibility with suction is well captured by the model, without adopting an apparent preconsolidation stress. Volume collapse during wetting is a direct result of a suction-dependent hardening law. The model predicts the volume shrinkage during drying of a slurry soil quite well.

Compared to existing models in the literature, the proposed SFG model seems to be more flexible in modelling different types of unsaturated soils. The model works well for soils that are dried or loaded from initially slurry conditions and for soils that have low to high air-entry values. It works for soils that are initially unsaturated in a similar way as existing models in the literature. In general, the SFG model is able to overcome some of the past limitations and questions that cannot be answered by existing elastoplastic models.

The SFG model provides a fundamental framework for modelling the basic features of unsaturated soil behaviour. As with its counterparts in the literature, it does not address more complex issues such as plastic volume expansion during wetting for expansive clays and volume collapse at zero mean stress for loess soils. The base model used for saturated states (i.e., the MCC model) is simplistic in nature and does not address issues like anisotropy, initial structure, and the dilation-contraction behaviour of sands. Some functions used in the proposed model may also have to be elaborated upon for quantitative prediction of unsaturated soil behaviour.

\section{References}

Alonso, E.E., Gens, A., and Josa, A. 1990. A constitutive model for partially saturated soils. Géotechnique, 40(3): 405-430.

Bolzon, G., Schrefler, B.A., and Zienkiewicz, O.C. 1996. Elastoplastic soil constitutive laws generalised to partially saturated states. Géotechnique, 46(2): 279-289.

Butterfield, R.A. 1979. Natural compression law of soils (an advance on $e-\log p^{\prime}$ ). Géotechnique, 29: 469-480.

Collins, I.F., and Kelley, P.A. 2002. A thermomechanical analysis of a family of soil models. Géotechnique, 52(7): 506-518.

Cui, Y.J., and Delage, P. 1996. Yielding and plastic behaviour of an unsaturated compacted silt. Géotechnique, 46(2): 291-311.

Dangla, P., Malinsky, L., and Coussy, O. 1997. Plasticity and imbibition-drainge curves for unsaturated soils: A unified approach. In Proceedings of the 6th International Symposium on Numerical Models in Geomechanics- NUMOG, July 1997, Montreal, Que. A.A. Balkema, Rotterdam. pp. 141-146.

Delage, P., and Graham, J. 1996. Mechanical behaviour of unsaturated soils: understanding the behaviour of unsaturated soils requires reliable conceptual models. In Proceedings of the $1 \mathrm{st}$ International Conference on Unsaturated Soils, September 1995. Paris. A.A. Balkema, Rotterdam. Vol. 3, pp. 1223-1256.

Estabragh, A.R., Javadi, A.A., and Boot, J.C. 2004. Effect of compaction pressure on consolidation behaviour of unsaturated silty soil. Canadian Geotechnical Journal, 41(4): 540-550. doi:10. 1139/t04-007. 
Fredlund, D.G. 1964. Comparison of soil suction and one-dimensional consolidation characteristics of a highly plastic clay. Technical Report No 245. Division of Building Research, National Research Council, Ottawa, Ont.

Fredlund, D.G., and Morgenstern, N.R. 1976. Constitutive relations for volume change in unsaturated soils. Canadian Geotechnical Journal, 13(3): 261-276. doi:10.1139/t76-029.

Fredlund, D.G., and Morgenstern, N.R. 1977. Stress state variables for unsaturated soils. Journal of the Geotechnical Engineering Division, 103(GT5): 447-466.

Fredlund, D.G., and Rahardjo, H. 1993. Soil mechanics for unsaturated soils. John Wiley \& Sons, New York.

Futai, M.M., and de Almeida, M.S.S. 2005. An experimental investigation of the mechanical behaviour of an unsaturated gneiss residual soil. Géotechnique, 55(3): 201-214.

Gallipoli, D., Gens, A., Sharma, R., and Vaunat, J. 2003. An elastoplastic model for unsaturated soil incorporating the effects of suction and degree of saturation on mechanical behaviour. Géotechnique, 53(1): 123-135.

Gens, A. 1996. Constitutive modelling: Application to compacted soils. In Proceedings of the 1st International Conference on Unsaturated Soils, September 1995, Paris. A.A. Balkema, Rotterdam. Vol. 3, pp. 1179-1200.

Gens, A., Sanchez, M., and Sheng, D. 2006. On constitutive modelling of unsaturated soils. Acta Geotechnica, 1(3): 137-147. doi:10.1007/s11440-006-0013-9.

Hashiguchi, K. 1995. On the linear relations of $v-\ln p$ and $\ln v-\ln$ $p$ for isotropic consolidation of soils. International Journal of Numerical and Analytical Methods in Geomechanics, 19(3): 367-376. doi:10.1002/nag.1610190505.

Hillel, D. 1971. Soil and water - Physical principles and processes. Academic Press, New York.

Houlsby, G.T. 1997. The work input to an unsaturated granular material. Géotechnique, 47(1): 193-196.

Jennings, J.E.B., and Burland, J.B. 1962. Limitations to the use of effective stresses in partly saturated soils. Géotechnique, 12(1): 125-144.

Jommi, C. 2000. Remarks on the constitutive modelling of unsaturated soils. In Experimental Evidence and Theoretical Approaches in Unsaturated Soils, Proceeding of International Workshop on Unsaturated Soil, 2000, Trento, Italy. A.A. Balkema, Rotterdam. pp. 139-153.

Josa, A., Balmaceda, A., Gens, A., and Alonso, E.E. 1992. An elastoplastic model for partially saturated soil exhibiting a maximum of collapse. In Computational plasticity III. Edited by D.R.J. Owen, E. Onate, and E. Hinton. Pineridge Press, Swansea. Vol. 1, pp. 815-826.

Kohgo, Y., Nakano, M., and Miyazaki, T. 1993. Theoretical aspects of constitutive modelling for unsaturated soils. Soils and Foundations, 33(4): 49-63.

Loret, B., and Khalili, N. 2002. An effective stress elastic-plastic model for unsaturated porous media. Mechanics of Materials, 34: 97-116. doi:10.1016/S0167-6636(01)00092-8.

Lloret, A., Villar, M.V., Sanchez, M., Gens, A., Pintado, X., and Alonso, E.E. 2003. Mechanical behaviour of heavily compacted bentonite under high suction changes. Géotechnique, 53: $27-40$.

Masin, D. 2005. A hypoplastic constitutive model for clays. International Journal for Numerical and Analytical Methods in Geomechanics, 29(4): 311-336. doi:10.1002/nag.416.

Matsuoka, H., Sun, D., Kogane, A., Fukuzawa, N., and Ichihara, W. 2002. Stress-strain behaviour of unsaturated soil in true triaxial tests. Canadian Geotechnical Journal, 39(3): 608-619. doi:10.1139/t02-031.
Ng, C.W.W., and Pang, Y.W. 2000. Influence of stress state on soil-water characteristics and slope stability. Journal of Geotechnical and Geoenviromental Engineering, ASCE, 126(2): 157166. doi:10.1061/(ASCE)1090-0241(2000)126:2(157).

Pham, H.Q., Fredlund, D.G., and Barbour, S.L. 2005. A study of hysteresis models for soil-water characteristic curves. Canadian Geotechnical Journal, 42(6): 1548-1568. doi:10.1139/t05071.

Roscoe, K.H., and Burland, J.B. 1968. On the generalised stressstrain behaviour of wet clay. In Engineering plasticity. Edited by J. Heyman and F. Leckie. Cambridge University Press, Cambridge. pp. 535-560.

Rouainia, M., and Muir Wood, D. 2000. A kinematic hardening constitutive model for natural clays with loss of structure. Géotechnique, 50(2): 153-164.

Santagiuliana, R., and Schrefler, B.A. 2006. Enhancing the BolzonSchrefler-Zienkiewicz constitutive model for partially saturated soil. Transport in Porous Media, 65(1): 1-30. doi:10.1007/ s11242-005-6083-6.

Sheng, D. 2003. Non-convexity of Barcelona Basic Model. International Journal for Numerical and Analytical Methods in Geomechanics, 27(10): 879-881. doi:10.1002/nag.299.

Sheng, D., Sloan, S.W., and Yu, H.S. 2000. Aspects of finite element implementation of critical state models. Computational Mechanics, 26(2): 185-196. doi:10.1007/s004660000166.

Sheng, D., Sloan, S.W., Gens, A., and Smith, D.W. 2003a. Finite element formulation and algorithms for unsaturated soils. Part I: Theory. International Journal for Numerical and Analytical Methods in Geomechanics, 27(9): 745-765. doi:10.1002/nag.295.

Sheng, D., Smith, D.W., Sloan, S.W., and Gens, A. 2003b. Finite element formulation and algorithms for unsaturated soils. Part II: Verification and application. International Journal for Numerical and Analytical Methods in Geomechanics, 27(9): 767-790. doi:10.1002/nag.296.

Sheng, D., Sloan, S.W., and Gens, A. 2004. A constitutive model for unsaturated soils: thermomechanical and computational aspects. Computational Mechanics, 33(6): 453-465. doi:10.1007/ s00466-003-0545-x.

Sloan, S.W., Abbo, A.J., and Sheng, D. 2001. Refined explicit integration of elastoplastic models with automatic error control. Engineering Computations, 18(1-2): 121-154. doi:10.1108/ 02644400110365842.

Sun, D.A., Matsuoka, H., and Xu, Y.F. 2004. Collapse behavior of compacted clays in suction-controlled triaxial tests. Geotechnical Testing Journal, 27(4): 362-370. doi:10.1520/GTJ11418.

Sun, D.A., Sheng, D., and Sloan, S.W. 2007a. Elastoplastic modelling of hydraulic and stress-strain behaviour of unsatuarated soil. Mechanics of Materials, 39(3): 212-221. doi:10.1016/j.mechmat. 2006.05.002.

Sun, D.A., Sheng, D., and Xu, Y.F. 2007b. Collapse behaviour of unsaturated compacted soil with different initial densities. Canadian Geotechnical Journal, 44(6): 673-686. doi:10.1139/T07-023.

Vaunat, J., Romero, E., and Jommi, C. 2000. An elastoplastic hydromechanical model for unsaturated soils. In Experimental Evidence and Theoretical Approaches in Unsaturated Soils, Proceeding of International Workshop on Unsaturated Soil, 2000, Trento, Italy. A.A. Balkema, Rotterdam. pp. 121-138.

Vanapalli, S.K., Fredlund, D.G., Pufahl, D.E., and Clifton, A.W. 1996. Model for the prediction of shear strength with respect to soil suction. Canadian Geotechnical Journal, 33(3): 379-392. doi:10.1139/cgj-33-3-379.

Vicol, T. 1990. Comportement hydraulique et mécanique d'un limon non saturé. Application à la modélisation. Thèse de Doctorat, École Nationale des Ponts et Chaussées, Paris, France. 
Wheeler, S.J. 1996. Inclusion of specific water volume within an elasto-plastic model for unsaturated soil. Canadian Geotechnical Journal, 33(1): 42-57. doi:10.1139/t96-023.

Wheeler, S.J., and Sivakumar, V. 1995. An elasto-plastic critical state framework for unsaturated soil. Géotechnique, 45(1): 35-53.

Wheeler, S.J., Sharma, R.S., and Buisson, M.S.R. 2003. Coupling of hydraulic hysteresis and stress-strain behaviour in unsaturated soils. Géotechnique, 53(1): 41-54.

\section{Appendix A: Derivation of the loading- collapse surface in the Barcelona basic model (BBM)}

The fundamental equation in the BBM is the volumetric relationship under a constant suction. The loading-collapse yield surface and the hardening law can all be derived from this equation

$$
[\mathrm{A} 1] \quad v=N_{\mathrm{r}}-\lambda_{\mathrm{s}} \ln \frac{\bar{p}_{\mathrm{c}}}{\bar{p}_{\mathrm{r}}}
$$

where $\bar{p}_{\mathrm{c}}$ is the preconsolidation stress, $\lambda_{\mathrm{s}}$ is the slope of the normal compression and is a function of the suction, and $N_{\mathrm{r}}$ is the specific volume at the reference net mean stress $\bar{p}_{\mathrm{r}}$. We note that all of the normal compression lines (NCLs) meet at the reference net mean stress $\bar{p}_{\mathrm{r}}$ in the BBM.

The plastic volumetric strain is then

$$
\mathrm{d} \varepsilon_{\mathrm{v}}^{\mathrm{p}}=\frac{\lambda_{\mathrm{s}}-\kappa}{v} \frac{\mathrm{d} \bar{p}_{\mathrm{c}}}{\bar{p}_{\mathrm{c}}}+\frac{1}{v} \ln \left(\frac{\bar{p}_{\mathrm{c}}}{\bar{p}_{\mathrm{r}}}\right) \mathrm{d} \lambda_{\mathrm{s}}
$$

For a soil that was consolidated to $\bar{p}_{\mathrm{c} 0}$ at full saturation, its initial yield surface can be found by setting $\mathrm{d} \varepsilon_{\mathrm{v}}^{\mathrm{p}}=0$ and then integrating along the yield surface

$$
\int_{\bar{p}_{\mathrm{c} 0}}^{\bar{p}_{\mathrm{c}}} \frac{1}{v} \frac{1}{\ln \left(\frac{\bar{p}_{\mathrm{c}}}{\bar{p}_{\mathrm{r}}}\right)} \frac{\mathrm{d} \bar{p}_{\mathrm{c}}}{\bar{p}_{\mathrm{c}}}+\int_{\lambda_{0}}^{\lambda_{\mathrm{s}}} \frac{1}{v\left(\lambda_{\mathrm{s}}-\kappa\right)} \mathrm{d} \lambda_{\mathrm{s}}=0
$$

where $\bar{p}_{\mathrm{c} 0}$ is the preconsolidation stress at zero suction, and $\lambda_{0}$ is the slope of the NCL at zero suction. The previous integration leads to

$$
\frac{\ln \frac{\bar{p}_{\mathrm{c}}}{\overline{\bar{p}}_{\mathrm{r}}}}{\ln \frac{\bar{p}_{\mathrm{c} 0}}{\bar{p}_{\mathrm{r}}}}=\frac{\lambda_{0}-\kappa}{\lambda_{\mathrm{s}}-\kappa} \quad \text { or } \quad \frac{\bar{p}_{\mathrm{c}}}{\bar{p}_{\mathrm{r}}}=\left(\frac{\bar{p}_{\mathrm{c} 0}}{\bar{p}_{\mathrm{r}}}\right)^{\frac{\lambda_{0}-\kappa}{\lambda_{\mathrm{s}}-\kappa}}
$$

This is, of course, the loading-collapse yield surface in the BBM.

It can be shown that isotropic loading under a constant suction from the current yield surface leads to the same yield function, which means loading under a constant suction does not change the shape of the yield surface in the BBM. A new yield surface represents a contour of the total plastic volumetric strain
[A5]

$$
\begin{aligned}
\int_{\bar{p}_{\mathrm{c} 0}}^{\bar{p}_{\mathrm{cn} 0}} \frac{\lambda_{0}-\kappa}{v} \frac{\mathrm{d} \bar{p}_{\mathrm{c} 0}}{\bar{p}_{\mathrm{c} 0}} & =\int_{\bar{p}_{\mathrm{c}}}^{\bar{p}_{\mathrm{cn}}} \frac{\lambda_{\mathrm{s}}-\kappa}{v} \frac{\mathrm{d} \bar{p}_{\mathrm{c}}}{\bar{p}_{\mathrm{c}}} \Rightarrow \frac{\bar{p}_{\mathrm{cn}}}{\bar{p}_{\mathrm{r}}} \\
& =\left(\frac{\bar{p}_{\mathrm{cn} 0}}{\bar{p}_{\mathrm{r}}}\right)^{\frac{\lambda_{0}-\kappa}{\lambda_{\mathrm{s}}-\kappa}}
\end{aligned}
$$

Equation [A5] is of the same form as eq. [A4]. It is assumed in this derivation that the specific volume $v$ along the current yield surface does not change, which is generally not true. Alternatively, if the specific volume in eq. [A1] is replaced by its logarithmic value $\ln v$, eq. [A5] would still hold.

For wetting under a constant mean net stress, it is no longer possible to prove that the yield function of the BBM will remain the same as eq. [A4].

\section{Appendix B: Incremental stress-strain relations}

The yield function is assumed to be

[B1] $f=q^{2}-M^{2}\left(\bar{p}-\bar{p}_{0}\right)\left(\bar{p}_{\mathrm{y}}-\bar{p}\right) \equiv 0$

The consistency condition can then be written as

$$
\begin{aligned}
{[\mathrm{B} 2] \quad \mathrm{d} f=\left(\frac{\partial f}{\partial \overline{\boldsymbol{\sigma}}}\right)^{\mathrm{T}} \mathrm{d} \overline{\boldsymbol{\sigma}}+\frac{\partial f}{\partial \bar{p}_{0}} \frac{\partial \bar{p}_{0}}{\partial s} \mathrm{~d} s+} & \frac{\partial f}{\partial \bar{p}_{\mathrm{y}}} \frac{\partial \bar{p}_{\mathrm{y}}}{\partial s} \mathrm{~d} s \\
& +\frac{\partial f}{\partial \bar{p}_{\mathrm{y}}} \frac{\partial \bar{p}_{\mathrm{y}}}{\partial \varepsilon_{\mathrm{v}}^{\mathrm{p}}} \mathrm{d} \varepsilon_{\mathrm{v}}^{\mathrm{p}} \equiv 0
\end{aligned}
$$

The strain decomposition and flow rule take the form

$$
\text { [B3] } \mathrm{d} \boldsymbol{\varepsilon}=\mathrm{d} \boldsymbol{\varepsilon}^{\mathrm{e}}+\mathrm{d} \boldsymbol{\varepsilon}^{\mathrm{p}}=\mathrm{d} \boldsymbol{\varepsilon}^{\mathrm{e}}+\dot{\Lambda} \frac{\partial g}{\partial \overline{\boldsymbol{\sigma}}}
$$

The elastic stress-suction-strain relation is assumed to take the form

$$
\begin{aligned}
& \mathrm{d} \boldsymbol{\varepsilon}^{\mathrm{e}}=\left(\mathbf{D}^{\mathrm{e}}\right)^{-1} \mathrm{~d} \overline{\boldsymbol{\sigma}}+\left(\underline{\mathbf{W}}^{\mathrm{e}}\right)^{-1} \mathrm{~d} s \\
& \text { or } \quad \begin{array}{r}
\mathrm{d} \overline{\boldsymbol{\sigma}}=\mathbf{D}^{\mathrm{e}} \mathrm{d} \boldsymbol{\varepsilon}^{\mathrm{e}} \\
\quad-\mathbf{D}^{\mathrm{e}}\left(\underline{\mathbf{W}}^{\mathrm{e}}\right)^{-1} \mathrm{~d} s=\mathbf{D}^{\mathrm{e}} \mathrm{d} \boldsymbol{\varepsilon}^{\mathrm{e}}-\mathbf{W}^{\mathrm{e}} \mathrm{d} s
\end{array}
\end{aligned}
$$

where $\mathbf{D}^{\mathrm{e}}$ is the elastic stress-strain matrix, $\underline{\mathbf{W}}^{\mathrm{e}}$ is the elastic suction-strain vector, and $\mathbf{W}^{\mathrm{e}}=\mathbf{D}^{\mathrm{e}}\left(\underline{\mathbf{W}}^{\mathrm{e}}\right)^{-1}$.

The plastic multiplier can be solved by replacing eqs. [B3] and [B4] into the consistency condition [B2]

$$
\dot{\Lambda}=\frac{\left(\frac{\partial f}{\partial \overline{\boldsymbol{\sigma}}}\right)^{\mathrm{T}} \mathbf{D}^{\mathrm{e}} \mathrm{d} \boldsymbol{\varepsilon}+\left[\frac{\partial f}{\partial \bar{p}_{0}} \frac{\partial \bar{p}_{0}}{\partial s}+\frac{\partial f}{\partial \bar{p}_{\mathrm{y}}} \frac{\partial \bar{p}_{\mathrm{y}}}{\partial s}-\left(\frac{\partial f}{\partial \overline{\boldsymbol{\sigma}}}\right)^{\mathrm{T}} \mathbf{W}^{\mathrm{e}}\right] \mathrm{d} s}{\left(\frac{\partial f}{\partial \overline{\boldsymbol{\sigma}}}\right)^{\mathrm{T}} \mathbf{D}^{\mathrm{e}} \frac{\partial g}{\partial \overline{\boldsymbol{\sigma}}}-\frac{\partial f}{\partial \bar{p}_{\mathrm{y}}} \frac{\partial \bar{p}_{\mathrm{y}}}{\partial \varepsilon_{\mathrm{v}}^{\mathrm{p}}} \frac{\partial g}{\partial \bar{p}}}
$$

The stress-strain relation can then be written as 
The incremental suction-water content relation can be written as

[B7] $\mathrm{d} \theta=-\lambda_{\mathrm{ws}} n \frac{\mathrm{d} s}{s}+S_{\mathrm{r}} \mathrm{d} \varepsilon_{\mathrm{v}}=-\lambda_{\mathrm{ws}} n \frac{\mathrm{d} s}{s}+S_{\mathrm{r}} \mathbf{m}^{\mathrm{T}} \cdot \mathrm{d} \boldsymbol{\varepsilon}$

where $n$ is the porosity, and $\mathbf{m}^{\mathrm{T}}=(1,1,1,0,0,0)$. The slope $\lambda_{\mathrm{ws}}$ should be replaced by $\kappa_{\mathrm{ws}}$ for suction changes along the scanning curve.

Using the following notations:

$$
\begin{aligned}
& \mathbf{D}^{\mathrm{ep}}=\mathbf{D}^{\mathrm{e}}-\frac{\mathbf{D}^{\mathrm{e}} \frac{\partial \mathrm{g}}{\partial \overline{\boldsymbol{\sigma}}}\left(\frac{\partial \mathrm{f}}{\partial \overline{\boldsymbol{\sigma}}}\right)^{\mathrm{T}} \mathbf{D}^{\mathrm{e}}}{\left(\frac{\partial \mathrm{f}}{\partial \overline{\boldsymbol{\sigma}}}\right)^{\mathrm{T}} \mathbf{D}^{\mathrm{e}} \frac{\partial \mathrm{g}}{\partial \bar{\sigma}}-\frac{\partial \mathrm{f}}{\partial \overline{\mathrm{p}}_{\mathrm{y}}} \frac{\partial \overline{\mathrm{p}}_{\mathrm{y}}}{\partial \varepsilon_{\mathrm{v}}^{\mathrm{p}}} \frac{\partial \mathrm{g}}{\partial \overline{\mathrm{p}}}} \\
& \mathbf{W}^{\mathrm{ep}}=-\frac{\mathbf{D}^{\mathrm{e}} \frac{\partial \mathrm{g}}{\partial \overline{\boldsymbol{\sigma}}}\left[\frac{\partial \mathrm{f}}{\partial \overline{\mathrm{p}}_{0}} \frac{\partial \overline{\mathrm{p}}_{0}}{\partial \mathrm{s}}+\frac{\partial \mathrm{f}}{\partial \overline{\mathrm{p}}_{\mathrm{y}}} \frac{\partial \overline{\mathrm{p}}_{\mathrm{y}}}{\partial \mathrm{s}}-\left(\frac{\partial \mathrm{f}}{\partial \overline{\boldsymbol{\sigma}}}\right)^{\mathrm{T}} \mathbf{W}^{\mathrm{e}}\right]}{{ }^{\mathrm{T}}} \\
& \left(\frac{\partial \mathrm{f}}{\partial \overline{\boldsymbol{\sigma}}}\right)^{\mathrm{T}} \mathbf{D}^{\mathrm{e}} \frac{\partial \mathrm{g}}{\partial \overline{\boldsymbol{\sigma}}}-\frac{\partial \mathrm{f}}{\partial \overline{\mathrm{p}}_{\mathrm{y}}} \frac{\partial \overline{\mathrm{p}}_{\mathrm{y}}}{\partial \varepsilon_{\mathrm{v}}^{\mathrm{p}}} \frac{\partial \mathrm{g}}{\partial \overline{\mathrm{p}}} \\
& \mathbf{R}=\mathrm{S}_{\mathrm{r}} \mathbf{m} \\
& \mathrm{G}=-\frac{\lambda_{\mathrm{ws}} \mathrm{n}}{\mathrm{s}} \quad \text { or } \quad \mathrm{G}=-\frac{\kappa_{\mathrm{ws}} \mathrm{n}}{\mathrm{s}}
\end{aligned}
$$

the final incremental stress-strain relationship can be written

[B8] $\quad\left(\begin{array}{c}\mathrm{d} \overline{\boldsymbol{\sigma}} \\ \mathrm{d} \theta\end{array}\right)=\left(\begin{array}{cc}\mathbf{D}^{\mathrm{ep}} & \mathbf{W}^{\mathrm{ep}} \\ \mathbf{R} & G\end{array}\right)\left(\begin{array}{c}\mathrm{d} \boldsymbol{\varepsilon} \\ \mathrm{d} s\end{array}\right)$

The rate of soil suction is kept on the right-hand side as the strain rate to be consistent with the displacement finite element method where pore pressures and displacements are first solved from equilibrium and continuity equations. 